\title{
Beyond Thrombosis: the Role of Platelets in Pulmonary Hypertension
}

\author{
Salina Nicoleau ${ }^{\text {a }}$, Beata Wojciak-Stothard ${ }^{\mathrm{a}^{*}}$ \\ ${ }^{a}$ National Heart and Lung Institute, Imperial College London, Hammersmith Campus, Du Cane Road W12 ONN, London, United Kingdom.
}

Received 12 August 2020; Accepted 29 October 2020

\begin{abstract}
Pulmonary Hypertension (PH) is a multifactorial and lethal disease, characterised by elevated pulmonary arterial pressure and progressive right heart failure. PH pathobiology rests on four pillars: vascular remodelling, vasoconstriction, inflammation and thrombosis. While vascular and inflammatory cells have been the focus of PH research over the past decades, platelets have received relatively less attention, despite their associations with key pathophysiological processes of the disease. Platelets contain a wide range of vasoactive, inflammatory and pro-thrombotic mediators, likely to promote $\mathrm{PH}$ development and progression. There is currently no cure for $\mathrm{PH}$, and platelet-associated pathways may help identify new therapeutic strategies. This review summarises available evidence on the role of platelets in different forms of $\mathrm{PH}$, and comments on the current state of platelet-targeting therapies. It also describes the latest advances in the in vitro technologies that enable exploration of platelet function under dynamic and physiologically relevant conditions.
\end{abstract}

Keywords: Pulmonary Hypertension; Platelets; Thrombosis; Vascular.

\section{Introduction}

Pulmonary Hypertension (PH) is a severe lung disease, characterised by elevated pulmonary arterial pressure (PAP), ultimately leading to right heart failure and death. The rise in lung blood pressure results from increased pulmonary vascular resistance (PVR) due to vasoconstriction, vascular remodelling [1] and thromboembolism [2]. PH is a recognised comorbidity of a variety of conditions, including left-sided heart and lung diseases [3].

The current classification, based on disease aetiology, divides PH into five groups: 1) Pulmonary Arterial Hypertension (PAH), 2) PH due to Left Heart Disease (LHD), 3) PH due to lung diseases and/or hypoxia, 4) Chronic Thromboembolic PH (CTEPH), and 5) PH with unclear multifactorial mechanisms (Figure 1).

While usually considered a rare disease, $\mathrm{PH}$ is becoming a common health issue across the world. PAH has an incidence of 2-10 cases per million adults per year in developed countries [4], with idiopathic PAH (IPAH) being the predominant subtype (50-60\% of PAH cases) as per registries from Europe and the USA [4-6]. PH related to LHD or chronic hypoxia is more widespread than PAH [7], with 50.2\% of patients with chronic obstructive pulmonary disease (COPD) experiencing mild PH [8]. Additionally, many studies have reported that at least $50 \%$ of patients with heart failure are diagnosed with PH [9, 10], with increasing reports of cases amongst African cohorts [11]. CTEPH prevalence and incidence remain hard to determine, due to the high number of patients undergoing pulmonary thromboendarterectomy (PTE), which is largely curative, and to the similarities between acute pulmonary embolism (PE) and pre-existing CTEPH symptoms [12]. Nevertheless, the crude annual CTEPH incidence has been estimated to be around 5 and 104 cases per 100000 population per year in Europe and the USA, respectively [13], with approximately $3 \%$ of acute PE survivors developing the disease [14].

* Corresponding author: b.wojciak-stothard@imperial.ac.uk

dol http://dx.doi.org/10.28991/SciMedJ-2020-0204-7

> This is an open access article under the CC-BY license (https://creativecommons.org/licenses/by/4.0/).

(C) Authors retain all copyrights. 


\section{Pulmonary Hypertension}

\begin{tabular}{|c|} 
1.Pulmonary arterial \\
hypertension \\
1.1 Idiopathic PAH \\
1.2 Heritable PAH \\
1.3 Drug and toxin induced \\
1.4 Associated with: \\
1.4.1 Connective tissue \\
disease \\
1.4.2 HIV infection \\
1.4.3 Portal hypertension \\
1.4.4 Congenital heart \\
diseases \\
1.4.5 Schistosomiasis \\
1' Pulmonary veno- \\
occlusive disease and/or \\
pulmonary capillary \\
hemangiomatosis \\
1" Persistent pulmonary \\
hypertension of the \\
newborn (PPHN)
\end{tabular}

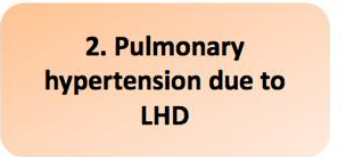

2.1 Left ventricular systolic dysfunction 2.2 Left ventricular diastolic dysfunction 2.3 Valvular disease 2.4 Congenital/acquired left heart inflow/outflow tract obstruction and congenital cardiomyopathies

\section{Pulmonary hypertension due to lung disease and/or chronic hypoxia}

\begin{tabular}{|c|}
\hline 3.1 Chronic obstructive \\
pulmonary disease \\
3.2 Interstitial lung disease \\
3.3 Other pulmonary \\
diseases with mixed \\
restrictive and obstructive \\
pattern \\
3.4 Sleep-disordered \\
breathing \\
3.5 Alveolar \\
hypoventilation disorders \\
3.6 Chronic exposure to \\
high altitude \\
3.7 Developmental lung \\
diseases
\end{tabular}

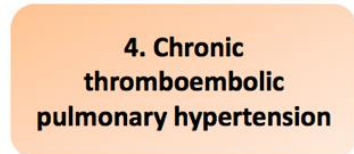
pulmonary hypertension

(n)

\begin{tabular}{|c|}
\hline 5. Pulmonary \\
hypertension with \\
unclear multifactorial \\
mechanisms \\
\hline 5.1 Hematologic \\
disorders: chronic \\
hemolytic anemia, \\
myeloproliferative \\
disorders, splenectomy \\
$\mathbf{5 . 2}$ Systemic disorders: \\
sarcoidosis, pulmonary \\
histiocytosis, \\
lymphangioleiomyomatosis \\
$\mathbf{5 . 3}$ Metabolic disorders: \\
glycogen storage disease, \\
Gaucher disease, thyroid \\
disorders \\
$\mathbf{5 . 4}$ Others: tumoral \\
obstruction, fibrosing \\
mediastinitis, chronic renal \\
failure, segmental PH \\
\hline
\end{tabular}

Figure 1. Latest classification of pulmonary hypertension (HIV: human immunodeficiency virus; LHD: Left-heart disease [15]

Considering the multifactorial nature of $\mathrm{PH}$, it is often challenging to identify the disease mechanisms and to design appropriate therapies [7]. However, regardless of the underlying conditions, the vast majority of PH patients display abnormalities in their pulmonary vascular bed, manifested by remodelling of all or some of the vascular layers (adventitia, media and intima) and a decreased luminal cross-sectional area [16, 17].

PH research has significantly evolved over the last century, since the first autopsy report of IPAH by Ernst von Romberg in 1891 [18]. The role of endothelial (ECs) and smooth muscle cells (SMCs) has been the main focus of research in the past decades. Medial hypertrophy is a common feature to all functional classes of PH, with major phenotypic [19], genetic [20-22] and epigenetic [23] alterations noted in pulmonary vascular smooth muscle cells (PVSMCs). ECs are also widely recognised as essential contributors to vascular remodelling and vasoconstriction, through dysregulated production of vasoactive mediators [24-26] and a switch towards a hyper-proliferative, antiapoptotic phenotype [27, 28]. Endothelial damage accompanied by loss of barrier function and followed by increased pro-thrombotic, pro-inflammatory, pro-proliferative and pro-angiogenic activation represent key events in initiation and progression of PH [29]. Inflammation plays an important role in disease development, although $\mathrm{PH}$ is not considered as an inflammatory disease per se. Indeed, PAH patients display elevated serum levels of cytokines and chemokines [30], and show increased perivascular immune cells infiltration in plexiform lesions in the lung [31].

While vascular and immune cells have been studied in great detail, platelets have received relatively less attention, despite their involvement in the main pathophysiological processes leading to PH. Platelets, through their ability to aggregate and to produce, store and release a wide range of growth factors, vasoactive mediators and cytokines [32], are likely to augment vascular remodelling and vasoconstriction, in addition to the formation of pulmonary thrombotic lesions observed in severe forms of $\mathrm{PH}[33]$.

Although there are clear associations between platelet dysfunction, thrombogenesis and vascular remodelling in $\mathrm{PH}$, the nature of their interdependent relationships is not fully understood. This review presents the current evidence for the role of platelets in PH pathobiology, first by looking at the upstream events leading to platelet activation, and then focusing on the interactions of platelets with the pulmonary vasculature. Current platelet-targeting therapies and pre-clinical models of platelet function are discussed. The latest advances in the in vitro technologies enabling observations of platelet behaviour under dynamic, physiologically relevant conditions, are also reviewed.

$\mathrm{PH}$ is a serious and currently incurable health condition [34] and more effective therapeutic strategies need to be developed. Targeting platelets and thrombotic processes could help manage the disease groups most affected by platelet dysfunction, and improve patients' quality of life. 


\section{Pulmonary Hypertension}

\subsection{Definitions and Symptoms}

$\mathrm{PH}$ is a haemodynamic and pathological condition defined by an increase in mean pulmonary arterial pressure (mPAP) to or above $25 \mathrm{mmHg}$ at rest, as measured by right heart catheterization [35].

Different haemodynamic definitions of PH are also available, based on combinations of PAP, pulmonary artery wedge pressure, cardiac output, diastolic pressure gradient and PVR, and are recommended to be used when distinction between isolated post-capillary hypertension and combined post- and pre-capillary hypertension is required $^{(4)}$. Pre-capillary PH usually encompasses PAH, CTEPH, PH due to lung disease, and idiopathic PH, while post-capillary PH includes PH due to LHD [36].

Common symptoms of $\mathrm{PH}$ are non-specific, usually related to progressive right ventricular dysfunction, and initially manifest upon exertion [7]. They include dyspnea, fatigue, chest pain, syncope and palpitations, which can also be observed at rest in severe cases [8]. Progressive lower extremity oedema, liver failure, and ascites may also develop due to chronically elevated right atrial (RA) pressure [8].

Because of the complex aetiology of $\mathrm{PH}$, and the variety of associated conditions, diagnosis requires careful planning and a multi-disciplinary approach. Right heart catheterization is considered the gold standard for PH diagnosis [36], but its invasiveness makes it unsuitable for routine use. Alternatives include electrocardiogram, chest radiography, echocardiography, pulmonary function test, computed tomography, and cardiac magnetic resonance imaging [36].

It is worth noting that elevated mPAP may not always have pathological cardiopulmonary causes, and can be observed in pregnancy, anaemia or sepsis. In such cases, the pulmonary bed remains unaffected, and PH resolves upon normalisation of the cardiac output [7].

$\mathrm{PH}$ prognosis remains poor, especially for $\mathrm{PAH}$, despite the available therapies. A mortality rate of more than $10 \%$ has been estimated in high-risk PAH patients one year after diagnosis [36], although recent evidence derived from the SERAPHIN and GRIPHON studies suggests that patients experiencing a morbidity event (eg worsening of symptoms) within the first 3 months of their enrolment had a mortality rate of 30-40\% [37].

\subsection{Pathobiology of Pulmonary Hypertension}

The complexity of PH can be attributed to a wide range of cellular and molecular alterations underlying its pathogenesis. Early hypotheses for the origin of vascular lesions included congenital thinning of the pulmonary artery (PA) media, and abnormal endothelial phenotypic modifications [38]. In 1958, Heath and Edwards published an extensive histological study of PH lungs, which provided the first detailed description of vascular remodelling [16]. It was in this study that increased PAP and PVR were linked to the formation of plexiform and dilation lesions, observed in advanced forms of the disease [16]. Another histological report by Yi and colleagues [17] described the obstructive intimal lesions in $\mathrm{PH}$ as 'intermediate forms between plexiform and thrombotic lesions', containing cells displaying a predominant myofibroblastic phenotype and different stages of differentiation.

Endothelial dysfunction is a hallmark of $\mathrm{PH}$, characterised by reduced production of vasorelaxants, such as prostacyclin $\left(\mathrm{PGI}_{2}\right)$ [24] and nitric oxide (NO) [25], and increased production of vasoconstrictors, such as endothelin-1 (ET-1) [23]. Additionally, increased release of transforming growth factors (TGFs) [39] and vascular endothelial growth factor (VEGF) [40] promote medial hypertrophy and intimal hyperplasia (Figure 2).

Phenotypic switches are commonly observed in both pulmonary artery endothelial cells (PAECs) and pulmonary artery smooth muscle cells (PASMCs). PH PAECs typically demonstrate a hyper-proliferative, pro-angiogenic and anti-apoptotic phenotype [27, 28], with evidence of endothelial-to-mesenchymal transition (EMT) [41] and compromised barrier function [42]. PH PASMCs show transition from contractile to synthetic phenotype, which promotes their hyperplastic growth [19]. SMCs arising from EMT [43], circulating fibrocytes or mesenchymal progenitor cells are thought to play a role in hypoxia-induced vascular remodelling [44]. Endothelial progenitor cells (EPCs) may also contribute to disease development [45], though some evidence suggests a protective role [46, 47].

In addition to vascular stresses induced by hypoxia, inflammation, drugs and toxins, genetic changes have also been shown to contribute to PH pathobiology, notably mutations in the TGF- $\beta$ receptors family. Indeed, bone morphogenic protein receptor II (BMPRII) mutations are found in approximately 53-86\% of hereditary PAH (HPAH), and $14-35 \%$ of IPAH patients [48], while other forms of PAH are characterised by reduced BMPRII function due to decreased expression [49] or increased degradation of the receptor expression [50]. Less commonly, mutations in the activin-like kinase-type $1(A L K 1)$, endoglin $(E N G)$ and $S M A D$ genes have been implicated in increased susceptibility to PAH [48]. Interestingly, only $20 \%$ of the BMPR2 mutations carriers develop the disease, suggesting that a "second hit" created by hypoxia, inflammation, drugs or toxins is required for disease progression [51, 52] (Figure 2). 
No specific genetic mutations have been linked to the other forms of $\mathrm{PH}[53,54]$, but there is evidence of a decreased expression of BMPR-1A, a transmembrane protein required for BMPRII signalling, in the lungs of CTEPH and other $\mathrm{PH}$ patients [55].

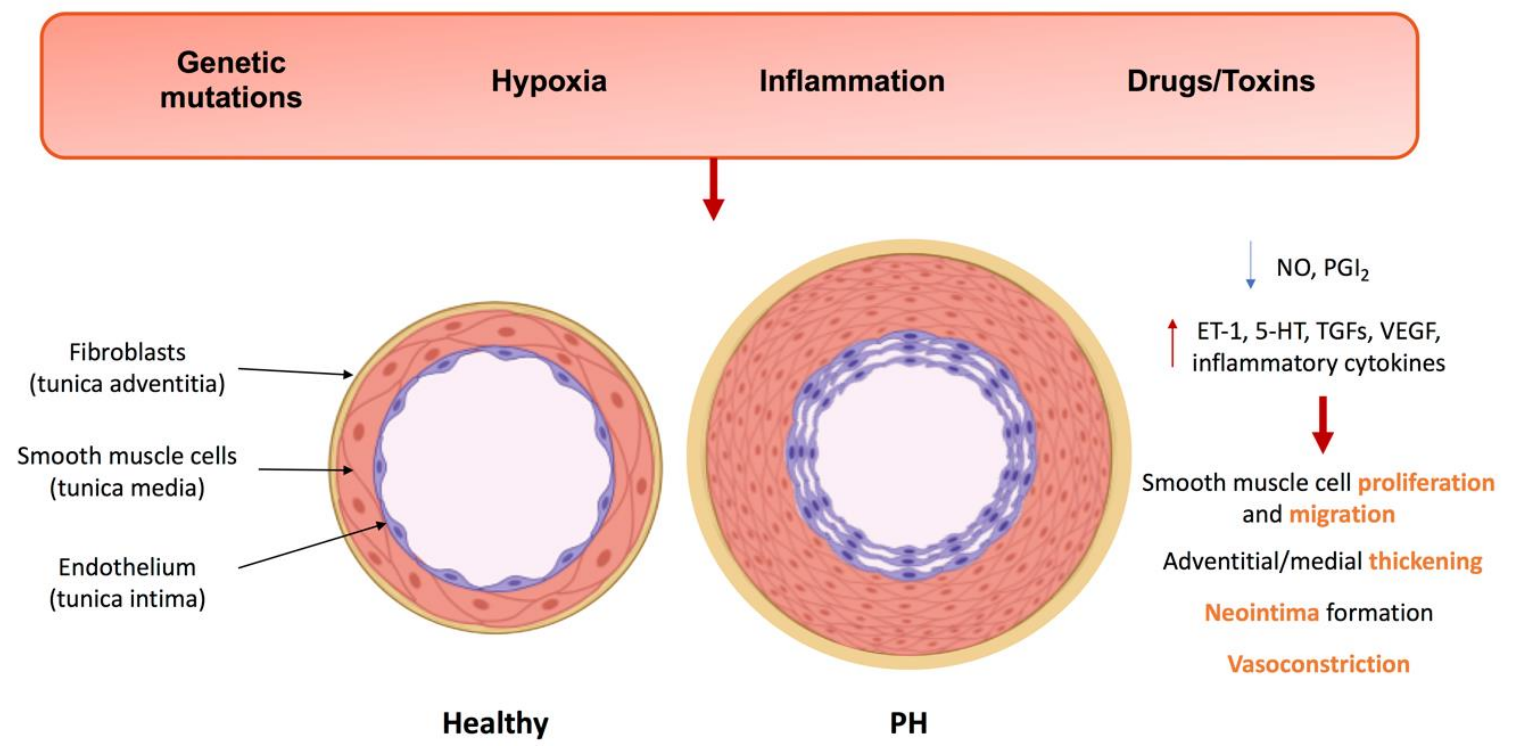

Figure 2. Abnormal vascular remodelling in pulmonary arterial hypertension

Genetic mutations, hypoxia, inflammation, drugs/toxins can cause endothelial dysfunction, leading to imbalances in the production and release of vasoactive mediators, mainly nitric oxide (NO), prostacyclin $\left(\mathrm{PGI}_{2}\right)$, serotonin (5-HT) and endothelin-1 (ET-1), growth factors (transforming growth factors (TGFs), vascular endothelial growth factor (VEGF)), and inflammatory cytokines. These all contribute to vasoconstriction, adventitial and medial thickening, as well as neointima formation, by promoting endothelial cells hypertrophy and hyperplasia, as well as smooth muscle cells and fibroblasts proliferation and migration. Such vascular changes ultimately cause an increase in pulmonary vascular resistance and pulmonary arterial pressure (Figure adapted from Schermuly et al, 2013 and Thompson and Lawrie, 2017) [1, 56].

\subsection{Pulmonary Hypertension and Thrombosis}

The potential role of thrombosis in the pathobiology of PH emerged in the 1970s, when Inglesby and colleagues first reported reduced plasma fibrinolysis in familial PH [57]. Many other studies have since found thrombotic lesions in the pulmonary vasculature of PAH patients $[33,58]$. In situ thrombosis is now widely recognised as a common pathological feature of PAH, and large central thrombi can also develop in severe IPAH [59].

CTEPH results from an incomplete resolution of pulmonary thromboemboli, which leads to the formation of organised, fibrotic occlusions within the vasculature, limiting blood flow and increasing PAP [12]. Histological examination of PTE specimens consistently showed intimal thickening with collagen deposition, inflammatory cells infiltration, atherosclerosis and calcification [60]. In contrast with PAH, which affects $<300 \mu$ m diameter vessels, CTEPH mostly involves the major pulmonary vessels [61] and can cause very severe PH if left untreated [62].

However, viewing CTEPH solely as a thrombotic obliteration of the central PA is too simplistic. Indeed, most of patients with acute pulmonary embolism do not develop CTEPH [14], which can persist even after PTE [63], suggesting that additional factors are required to induce the disease.

Many controversies remain around the pathobiology of CTEPH. Although less than 50\% of PTE patients were found to have coagulation or haematologic abnormalities in a retrospective study [60], the European CTEPH Registry reported that previous PE and deep venous thrombosis were present in $74.8 \%$ and $56.1 \%$ of CTEPH patients, respectively [64]. Furthermore, risk factors for recurrent venous thromboembolism are observed in CTEPH, including lupus anticoagulant and antiphospholipid antibodies [65], elevated plasma factor VIII and von Willebrand Factor (VWF):Antigen levels [66].

Ineffective fibrinolysis may also play a key role in CTEPH, as suggested by the presence of lysis-resistant fibrin variants in CTEPH patients [67, 68]. Additionally, CTEPH is often associated with chronic infection or inflammation [69], and elevated levels of inflammatory cytokines (eg Interleukin-6 (IL-6), Monocyte Chemoattractant Protein-1 (MCP-1)) have been reported in patients [70]. Splenectomy has also been associated with higher CTEPH incidence 
and worse prognosis [69]. These observations suggest that inflammation, abnormal platelet function and fibrinolysis create a pro-thrombotic environment, promoting vascular occlusion.

The hypothesis that increased PAP and PVR in CTEPH are caused not only by arterial obstruction, but also by vascular remodelling and vasoconstriction, is supported by the absence of correlation between the increased PAP and the degree of vascular bed obstruction [71]. Indeed, CTEPH patients have much higher PVR than acute PE patients with similar vascular bed obstruction levels [63]. This suggests that PE may be an initiating event, but is not sufficient to cause CTEPH, which actually results from the secondary pulmonary vasculopathy that follows thromboembolism.

Histological studies of CTEPH lungs revealed vascular changes similar to those seen in other forms of PH, including the formation of plexiform lesions [17, 71]. Interestingly, vascular remodelling was also observed in distal PAs which were not directly affected by thrombi [17], but were exposed to high PAP and shear stress due to chronic obstruction of the main arteries. A "dual vascular bed compartment" theory for CTEPH was first suggested by Moser and colleagues [72], whereby patients display an obstructed compartment subjected to chronic ischemia, and an unobstructed one subjected to increased blood flow. Both regions display vasculopathy, but induced by different causes.

CTEPH therefore appears as a multifaceted disease, in which major vessel thrombosis and remodelling is accompanied by pulmonary arteriopathy, characterised by endothelial dysfunction and excessive ECs and SMCs proliferation [72]. EMT [73] and progenitor cells [74] have also been suggested to participate in CTEPH progression.

Whilst the predominant view is that PE, followed by progressive vascular remodelling leads to CTEPH, it has also been argued that primary pulmonary arteriopathy can induce secondary in situ thrombosis and vascular occlusion [75]. Similarities between CTEPH and other forms of PH, such as pulmonary thrombosis and plexiform lesion formation $[33,58]$, are indicators of a complex aetiology of the disease.

\section{Platelet Dysfunction in Pulmonary Hypertension}

The role of platelets and thrombosis in PH remains controversial. Platelet activation and aggregation can either be regarded as an active regulator of vascular remodelling, or it can be seen as a passive bystander, secondary to endothelial dysfunction and pulmonary arteriopathy. This section discusses the physiological role of platelets and describes the mechanisms leading to platelet aggregation and dysfunction in $\mathrm{PH}$.

\subsection{The Physiological Role of Platelets in the Human Body}

Discovered by Giuilio Bizzozero in 1882 [76], platelets are small, anucleate cell fragments (2-3 $\mu$ m diameter) derived from megakaryocytes [77] that circulate in the bloodstream and have an essential role in the regulation of haemostasis and vascular integrity. Platelet dysfunction has been implicated in a wide range of diseases, including cardiovascular diseases (CVDs) and cancer [78].

Thousands of platelets can be produced by a single megakaryocyte, and around $10^{11}$ platelets are made every day in a healthy adult [79], with old platelets being destroyed in the spleen and liver by Kupffer cells [80]. Platelets express a variety of surface receptors, regulating their interactions with the endothelium and other platelets, and the release of their granule contents [78].

Under normal physiological conditions, interaction of platelets with vascular cells and soluble coagulation proteases (called coagulation factors) maintains the haemostatic balance, preventing thrombosis and haemorrhage [81]. Coagulation, initially described as a cascade of events initiated by two distinct pathways, known as the "extrinsic" and "intrinsic" pathways [81], is now viewed as a three-phase model of overlapping initiation, amplification and propagation of the response [82]. Coagulation ultimately leads to the formation of a fibrin mesh, which stabilises the pre-formed platelet plug [82]. Detailed mechanisms of this process have been reviewed elsewhere [83].

The tissue factor (TF)/factor VIIa complex is essential in initiating haemostasis [82]. TF is highly expressed in the vascular adventitia, but less so in ECs and SMCs in healthy blood vessels [84]. However, changes in blood flow [85], hypoxia [86], growth factors (including platelet-derived growth factors (PDGF)) [87] and inflammation [88] can affect endothelial TF expression. An overview of the coagulation cascade, initiated by endothelial TF, is provided in Figure 3. TF can also be found in circulation, in association with platelet-derived microparticles (PMPs) [89].

Upon tissue injury and sub-endothelial collagen exposure, platelets are captured by VWF, which binds the platelet GPIb/V/IX receptor complex [90]. This leads to platelet activation and shape changes, followed by GPIIb/IIIa surface expression, which mediates inter-platelet interactions via VWF or fibrinogen binding [91]. VWF usually substitutes for fibrinogen under high shear stress (HSS) conditions [92]. Activated platelets then recruit additional ones through the release of agonists, such as adenosine 5'-diphosphate (ADP), serotonin or thromboxane A-2 (TXA-2) [32], consolidating the formation of the platelet plug. Platelets may adhere to the endothelium in the absence of evident 
endothelial injury, a process which will be described later in this review.

Platelets also act as an important link between primary and secondary haemostasis, which involves stabilisation of the pre-formed platelet plug by insoluble fibrin, the end-product of the coagulation cascade [81]. Platelets contribute to this process by exposing a negatively charged phospholipid surface, required for the catalytic activity of coagulation factor complexes [93].

Many pro-inflammatory, pro-thrombotic, and pro-angiogenic mediators are stored in platelets' $\alpha$ - and dense $(\delta)$ storage granules, and are released upon platelet activation [32]. P-selectin, TGF $\beta$-1, VWF, PDGF, tumour necrosis factor- $\alpha$ (TNF- $\alpha$ ), interleukins, coagulation Factor V and fibrinogen are found in platelets' $\alpha$-granules [94]. Dense granules contain many vasoactive molecules, including serotonin (5-HT), ADP, adenosine 5'-triphosphate (ATP), calcium and catecholamines [95]. All these molecules are known to induce endothelial inflammation, SMC migration and proliferation, platelet aggregation and leukocyte migration [1], suggesting a potential role of platelets in $\mathrm{PH}$ pathogenesis.

The role of platelets therefore extends beyond thrombosis and haemostasis, with strong evidence of their involvement in vascular inflammation, atherosclerosis [96], arthritis [97] and PH associated with inflammatory and connective tissue diseases, including systemic sclerosis [98] and systemic lupus erythematosus [99].

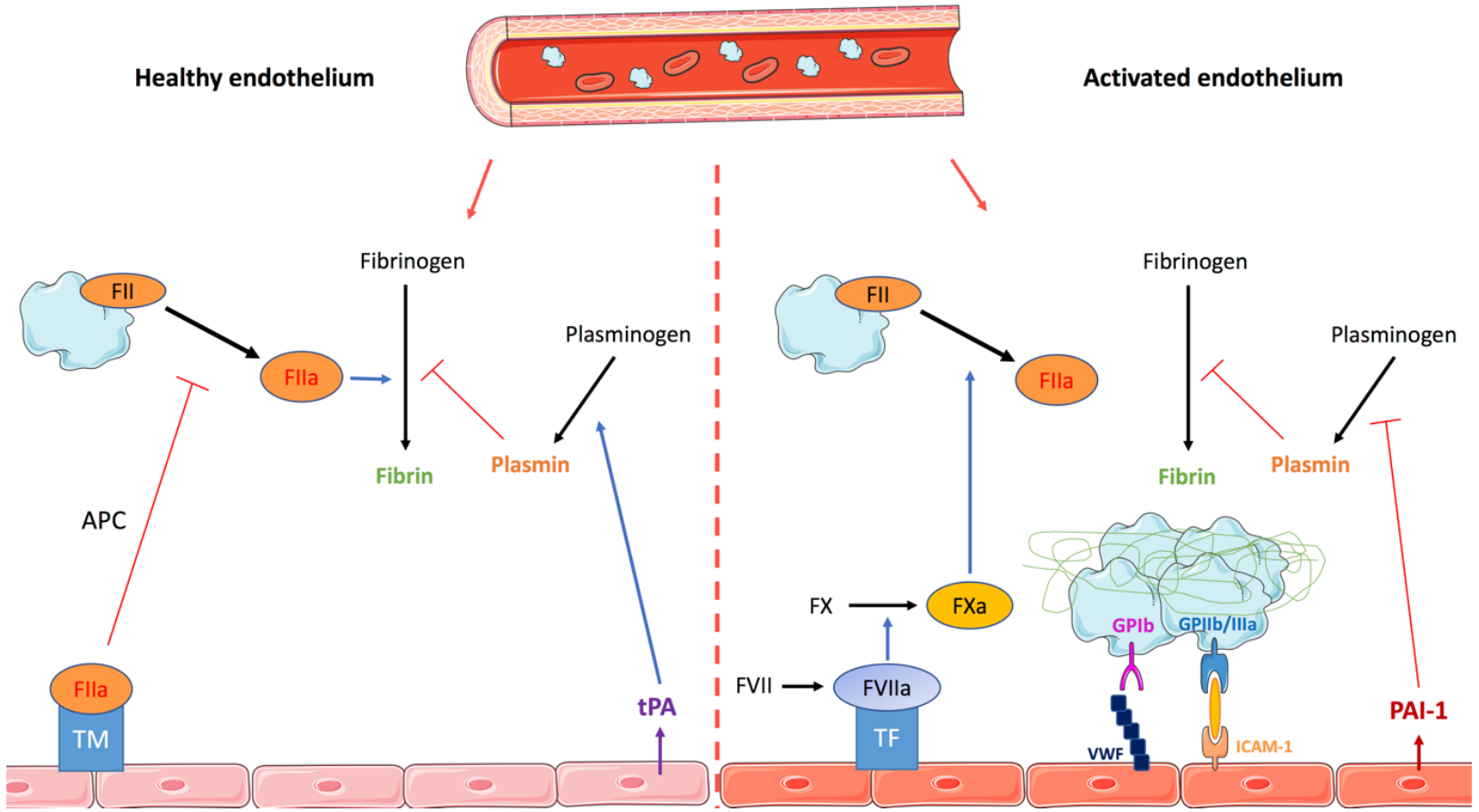

Figure 3. Overview of the coagulation cascade initiated by endothelial tissue factor

When activated, the endothelium expresses increases expression of tissue factor (TF), which binds and activates factor VII (FVII), leading to factor X (FX) activation. FXa then cleaves platelet- and endothelium-bound pro-thrombin (FII) into thrombin (FIIa), which in turn cleaves fibrinogen into fibrin. Platelets adhere to the activated endothelium by binding to von Willebrand factor (VWF) through the GPIb receptor, and to intercellular adhesion molecule-1 (ICAM1) via GPIIb/IIIa, an interaction mediated by extracellular matrix proteins such as fibrinogen. Fibrin forms a mesh and stabilises the pre-formed platelet plug. The coagulation cascade is tightly regulated by endothelium-derived factors. Secreted tissue plasminogen activator (tPA) promotes the activation of plasminogen into plasmin, an inhibitor of fibrin formation. This process is inhibited by plasminogen activator inhibitor-1 (PAI-1), which is increased in pulmonary arterial hypertension. Additionally, thrombomodulin (TM) binds to thrombin, converting it into an anti-coagulant catalysing the activation of protein $\mathrm{C}$ (APC), which in turn inhibits thrombin production.

\subsection{Platelet-vessel Wall Interactions}

The endothelium maintains vascular integrity and regulates haemostasis, preventing excessive coagulation and thrombus formation. An intact, healthy endothelium displays an anti-thrombotic surface, mainly through the expression of thrombomodulin (TM), which binds thrombin and prevents fibrinogen cleavage [100] (Figure 3). ECs can also produce tissue plasminogen activator (t-PA) and plasminogen activator inhibitor-1 (PAI-1), therefore potentiating or inhibiting fibrinolysis [101]. Additionally, the endothelium is a major source of $\mathrm{NO}_{\text {[102] and PGI }}$ [103], which are key inhibitors of platelet aggregation and activation[104], in addition to their vasodilatory and antiproliferative effects $[102,103]$. 
However, inflammation, chronic hypoxia or shear stress can lead to endothelial activation and a switch towards a pro-thrombotic phenotype $[86,105,106]$, resulting in imbalanced production of haemostatic and vasoactive mediators. PH patients typically display a hypercoagulable state, characterised by increased thrombin activity [107], increased plasma VWF [108] and PAI-1 [107] levels and reduced TM levels [109]. Aberrant TF expression has also been observed in vessels and plexiform lesions of PAH lungs[110], with higher levels of VWF associated with worse disease outcomes [108, 111]. Furthermore, impaired endothelial function leads to reduced NO [25] and PGI 2 [24] production, which not only promotes vasoconstriction [112], but also platelet activation and aggregation [113].

Platelets can directly bind to the vascular endothelium, in addition to their interactions with the sub-endothelial matrix and other platelets. This direct interaction is particularly important during inflammation. Under physiological conditions, platelets roll on the vascular wall, and their binding is enhanced upon endothelial activation, leading to firm adhesion [114]. Platelet-endothelial interactions are mediated by integrins and selectins, and comprise tethering, rolling and adhesion, bearing similarities to the leukocyte adhesion process [115] (Figure 4). P-selectin is essential for platelet rolling, particularly on the inflamed endothelium [114]. While P-selectin is expressed both by platelets [94] and ECs [116], only endothelial P-selectin is involved in platelet-endothelial interactions under stimulated conditions [114]. Like P-selectin, endothelial VWF is also stored in Weibel-Palade bodies and is released upon stimulation [117], binding to the GPIb $\alpha$ subunit of the GPIb/V/IX complex [118]. VWF is key for promoting platelet adhesion under high shear stress, enabling platelet-VWF interactions to sustain shear rates above $500 \mathrm{~s}^{-1}[105,119]$. Particularly, ultralarge VWF multimers, released by activated ECs [120], have the ability to form very strong bonds with platelet GPIb $\alpha$ [121]. However, due to its fast dissociation rate [122], GPIb $\alpha$-VWF binding is considered to be involved in initial and reversible platelet adhesion, rather than irreversible binding to the endothelium [123]. Interestingly, long-lasting GPIb $\alpha$-VWF interactions appear to occur under abnormally high shear rates, above $10,000 \mathrm{~s}^{-1}$ [124].

P-selectin glycoprotein ligand 1 (PSGL-1) [125] and GPIb $\alpha$ [126] are main P-selectin ligands on platelets. ECs can also express PSGL-1, which binds platelets' P-selectin after endothelial TNF- $\alpha$ stimulation [127]. The exact roles of endothelial and platelet PSGL-1 and P-selectin under physiological and pathological conditions remain to be explored.

In contrast with short-lived, selectin-mediated interactions, integrins are involved in stable platelet adhesion (Figure 4). Stable adhesions are initiated by GPIIb/IIIa on platelets, and $\alpha v \beta 3$, Intercellular Adhesion Molecule-1 (ICAM-1) and VWF on ECs [128, 129]. Fibrinogen and vitronectin can bind to $\alpha v \beta 3$ and ICAM-1, therefore acting as a bridge between platelets and ECs [130]. ICAM-1[131] and $\alpha v \beta 3$ [132] expression and VWF production levels [120] are low under resting conditions, but can increase significantly upon endothelial activation, promoting platelet adhesion. Elevated ICAM-1 levels have been found in PAH [133] and CTEPH [134] patients, suggesting an increased risk for platelet-mediated pathological effects.

Of relevance to $\mathrm{PH}$, an impairment of endothelial barrier function due to BMPRII mutations [135], hypoxia or other $\mathrm{PH}$ factors, may lead to sub-endothelial collagen and laminin exposure, promoting platelet adhesion and aggregation.

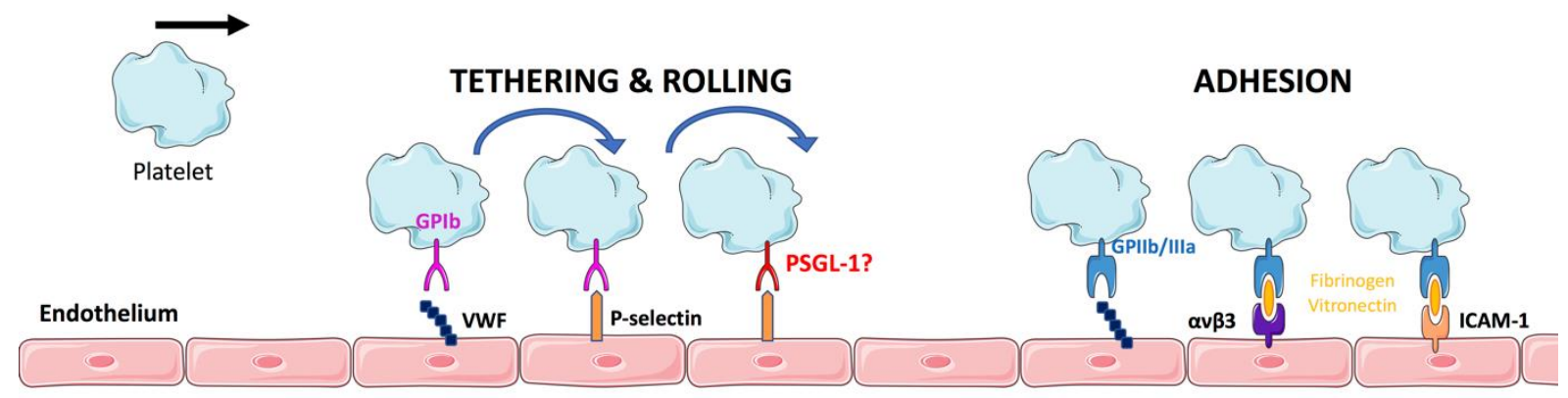

Figure 4. Platelet rolling and adhesion to the vascular endothelium

Platelets can directly bind to the vascular endothelium through tethering, rolling and adhesion, enhanced upon endothelial activation. Under high shear stress conditions, immobilised von Willebrand Factor (VWF) captures platelets and initiates their reversible binding via Glycoprotein Ib (GPIb). P-selectin also binds to GPIb, and potentially to P-selectin glycoprotein ligand 1 (PSGL-1), promoting platelet rolling. Stable adhesion of platelets is mediated by platelet and endothelial integrins, notably $\alpha v \beta 3$ and Intercellular Adhesion Molecule-1 (ICAM-1) on endothelial cells, and Glycoprotein IIb/IIIa (GPIIb/IIIa) on platelets. Extracellular matrix proteins, such as fibrinogen or vitronectin, act as a bridge between platelets and the endothelium by binding their respective integrins. VWF is also required for stable platelet adhesion, especially under high shear stress. 


\subsection{Platelet Abnormalities in Pulmonary Hypertension}

Platelet dysfunctions are commonly found in $\mathrm{PH}$, and can range from metabolic alterations to phenotypic changes and defective aggregation.

Platelet metabolic abnormalities, such as increased mitochondrial reserve capacity, have been correlated with mPAP, PVR and RV stroke work index in PAH patients [136]. Thrombocytopenia has also been observed in patients with severe forms of PAH [137], likely due to microangiopathic haemolysis, a process in which flow through fibrin clots and plexiform lesions results in platelets shearing [138]. In contrast, increased levels of the thrombopoiesisstimulating hormone thrombopoietin have been reported in pulmonary vessels of PH patients [139]. Additionally, increased mean platelet volume (MPV), indicative of platelet activation [140], was found in IPAH and in conjunction with decreased platelet count in CTPEH patients, suggesting increased platelet turnover [141]. Platelet production and destruction therefore seem to be altered in $\mathrm{PH}$.

Platelet activation is higher in PH patients compared with healthy individuals. In CTEPH patients, platelets show hyperresponsiveness to thrombin stimulation, as well as increased activation of the small GTPase RalA, which is involved in degranulation [142]. Interestingly, platelet RhoA but not RalA was found to be increased in PAH patients [142], likely to reflect different pathophysiology of both diseases. RhoA plays a role in cytoskeletal reorganisation [143] and platelet aggregation [144].

Greater platelet agonist-induced aggregation was also found in CTEPH [141] and PAH patients [145]. Tyrosine phosphorylation, used as a marker of in vivo platelet activation, is increased by $79 \%$ in PAH patients, compared with controls [146]. Genome-wide RNA expression analyses of IPAH lung tissues showed that gene expression of proteins involved in coagulation, platelet activation and degranulation, including platelet factor $4(P F 4), \mathrm{P} 2 \mathrm{Y}$ purinoreceptor 1 $(P 2 R Y 1)$, and coagulation factor II (thrombin) receptor-like $3(F 2 R L 3)$ was elevated, suggesting abnormal endogenous activation in platelets [147]. Additionally, platelets from PAH patients release soluble CD40L (sCD40L), a key proinflammatory molecule, at a higher level in response to thrombin receptor-activating peptide (TRAP), compared with controls [148].

Platelets can produce NO via eNOS and iNOS expression, though their role in this process is debatable [149, 150]. Reduced expression of platelet eNOS is reduced in PAH patients [151] can potentially lower their activation threshold. NO regulates platelets' intracellular $\mathrm{Ca}^{2+}\left(\mathrm{Ca}^{2+}\right)$, which controls platelet activation and aggregation [152]. Indeed, abnormalities in $\mathrm{Ca}^{2+}{ }_{\mathrm{I}}$ homeostasis have been associated with reduced $\mathrm{NO}$ levels both in experimental models of arterial hypertension [153] and hypertensive human patients [154], and elevated $\left[\mathrm{Ca}^{2+} \mathrm{I}\right.$. was found to enhance platelets' sensitivity to agonist stimulation [153]. These observations may, at least in part, may explain the correlation between platelet hyper-aggregability and reduced $\mathrm{NO}$ levels observed in $\mathrm{PH}$.

\subsection{Shear Stress and Thrombotic Responses}

Platelet aggregation is largely influenced by shear stress and changes in blood flow. In particular, shear acceleration and deceleration, also known as shear micro-gradients, create a pro-thrombotic environment [105, 155]. As previously mentioned, ECs orchestrate vascular responses to haemodynamic stimuli, through their ability to sense wall shear stress (WSS) via specific cell-surface mechanosensors [156]. While laminar, pulsatile flow with physiological WSS (mean 10-15 dyne $/ \mathrm{cm}^{2}$, peak $<100$ dyne $/ \mathrm{cm}^{2}$ ) promotes endothelial quiescence, disturbed flow and low WSS $\left(<4\right.$ dyne $/ \mathrm{cm}^{2}$ ) have been shown to induce endothelial dysfunction, including high EC turnover, random actin alignment [157], increased permeability [157], increased expression of pro-inflammatory markers, such as MCP1 [158] and ICAM-1 [157, 158], and increased secretion of VWF [105].

Shear stress also regulates VWF function, by causing important conformational changes in its A1, A2 and A3 domains and regulating its interactions with platelets [159]. Especially, high shear stress exposes the A1 domain, allowing it to form a stable complex with platelet GPIb $\alpha$ [160].

In vivo and in vitro studies, using stenosed microfluidic chambers, have previously shown that high WSS at the stenosis apex promotes reversible GPIb-mediated platelet recruitment, while low WSS downstream the stenotic region led to stable platelet aggregation via GPIIb/IIIa activation and in a VWF-dependent manner [105, 155]. Elongational flow was found to activate soluble VWF, high WSS to promote TXA-2 and ADP release from platelets, and decreasing WSS to induce endothelial VWF secretion and accumulation at the stenosis outlets [105]. Interestingly, platelet aggregation did not occur in straight microfluidic channels, even at very high shear rates (up to 20000s ${ }^{-1}$ ) [105, 155], indicating a key role for stenotic geometries in thrombogenesis. This is of relevance in the context of vascular remodelling in $\mathrm{PH}$, as luminal obstruction could create flow perturbations, therefore promoting in situ platelet aggregation. 


\section{The Role of Platelets in Pulmonary Hypertension Pathogenesis}

Platelets, through their aggregation into thrombi and the production of a variety of vasoactive mediators, growth factors and inflammatory cytokines, contribute to vascular remodelling, vasoconstriction and the formation of occlusive thrombotic vascular lesions. This section will explore how platelets are related to each of these events.

\subsection{Vascular Remodelling}

Disordered angiogenesis is found in severe $\mathrm{PH}$, usually in the form of angioproliferative, plexiform lesions [161]. A plethora of pro- and anti-angiogenic factors, including VEGF, PDGF, PF4 and angiostatin are released by platelets [94] (Figure 5). Beside angiogenesis, VEGF controls many fundamental functions of vascular cells, from apoptosis to NO production [162]. However, the role of VEGF in PH remains controversial. While some studies found that VEGF overexpression in MCT-[163] and chronic hypoxia-[164] induced PH rats led to haemodynamic improvements, others showed that inhibition of VEGF signalling attenuates PH [165]. Furthermore, despite the evidence for increased VEGF receptor-2 (VEGFR-2) expression in plexiform lesions of PH patients [161], VEGFR blockade causes severe PH when combined with chronic hypoxia in rats [166]. In humans, one study found increased platelet VEGF content in PH patients [167], but other studies observed no differences in plasma [168] and platelet [169] VEGF levels between IPAH and controls. VEGF administration after ECs accumulation in the pulmonary vasculature of chronic hypoxia rats had a slightly negative impact on PAP [166], suggesting that VEGF may have a dual role in PH, providing early protection before contributing to vascular remodelling. VEGF has also been shown to promote TF expression in ECs [170].

PDGF acts as a mitogen [171] and chemoattractant[172] for PASMCs, and PDGF receptor (PDGFR) expression is increased in PAH lungs [173, 174]. Consistently, inhibition of PDGFRs reverses experimental PH [175].

Angiostatin is another platelet-derived factor released upon aggregation [176] (Figure 5), which promotes EC apoptosis by antagonising VEGF [177]. Indeed, higher levels of platelet angiostatin in IPAH patients have been associated with increased EC apoptosis [169]. Additionally, adenoviral overexpression of angiostatin was shown to aggravate PAH in chronically hypoxic mice [178].

Platelet activating factor (PAF) has been shown to induce IL-6/8 [179] and VEGF [180] expression in pulmonary fibroblasts and vascular SMCs, and has been associated with increased disease severity in primary pulmonary hypertension of the newborn (PPHN) [181] and chronic hypoxia-induced PH [182]. In foetal lambs exposed to chronic high-altitude in utero, increased PAF levels and PAF-induced PASMCs proliferation were observed [183], while PAFreceptor antagonists attenuated hypoxia-induced PH and vascular remodelling in rat models [182].

Serotonin produced by the central nervous system is initially taken up by platelets [184] to prevent its vasoconstrictive [185], pro-proliferative [20] and pro-thrombotic [186] effects. While some studies found increased circulating serotonin levels in PH patients [187, 188], others did not [189, 190]. Higher serotonin release from platelets was also observed in PH patients compared to controls [187]. Secreted upon platelet activation, serotonin has a powerful vasoconstricting effect (Figure 5) and acts on many vascular cells through the serotonin transporter (SERT) and three serotonin receptors: 5-HT-1BR, 5-HT-2AR and 5-HT-2BR. Elevated levels of all these receptors have been found in PH lungs[191, 192], although only the expression of SERT was increased in cultured patient-derived PASMCs, and accounted for the serotonin-induced PASMCs growth response [192].

The importance of serotonin in vascular remodelling was first suggested in the 1960s, when an increased number of female PAH cases was associated with the intake of the anorectic drug Aminorex [193], known to affect serotonin transport in the lungs [194]. Increased SERT activity was shown to promote $\mathrm{Ca}^{2+}$-dependent, Rho-associated protein kinase (ROCK)-mediated PASMC proliferation in vitro [195], as well as contraction through voltage-gated $\mathrm{Kv}$ channels inhibition [196]. Additionally, SERT gene polymorphism was found in $65 \%$ of PH patients, compared to $27 \%$ of controls [20].

Serotonin may also be involved in EPC differentiation [191], fibroblasts proliferation [197] and metabolic alterations in PAH [198]. Furthermore, it could promote inflammatory cells transmigration by increasing endothelial permeability [199], and platelet aggregation mediated by the 5-HT-2AR [200].

Angiopoietin-1, also released from platelets upon thrombin stimulation [201], has been proposed to stimulate endothelial serotonin production by activating TIE-2 receptors, further promoting PASMC proliferation [202].

\subsection{Inflammation}

Platelets release many mediators increasing endothelial dysfunction, inflammation, and leukocyte recruitment, which promote vascular remodelling. There is a close link between coagulation and vascular inflammation, and CTEPH patients typically display increased levels of inflammation markers, including C-Reactive Protein (CRP) [203] and TNF- $\alpha$ [204]. 
CD40L is an important pro-inflammatory molecule, expressed on the surface of activated platelets, and released as sCD40L [205] (Figure 5). Elevated levels of sCD40L have been found in PAH patients, alongside increased MCP-1 and IL-8 [148], and sCD40L has been shown to induce EC [206] and fibroblast [207] chemokine production, promoting leukocytes infiltration. Interactions between sCD40L and its endothelial receptor CD40 are known to induce vascular remodelling in other diseases, including atherosclerosiss [208], and could therefore participate in the development of PAH.

The pro-angiogenic chemokine stromal-derived factor-1a (SDF-1a) (also known as CXCL12) has been shown to induce monocyte chemotaxis [209] (Figure 5), and promote vascular remodelling through its receptors CXCR4 [210] and CXCR7 [211], notably by recruiting bone marrow-derived progenitor cells [210]. Increased CXCR7 [211, 212] and SDF-1a [212] levels were found both in PH patients' and mice models' lungs, and have been associated with poorer PAH survival [213].

Lymphotoxin-like inducible protein that competes with glycoprotein $\mathrm{D}$ for Herpesvirus entry mediator on $\mathrm{T}$ lymphocytes (LIGHT) is a platelet-derived TNF- $\alpha$ superfamily member [214], known to promote EC- and monocytesmediated vascular inflammation [215] (Figure 5). Elevated serum LIGHT levels have been found in the femoral arteries of IPAH, CTEPH and secondary PAH patients, and correlated with increased mortality [216]. LIGHT receptors were also detected on PASMCs, PAECs and alveolar macrophages in PAH patients' lungs, and PAECs showed increased TF and PAI-1, as well as decreased TM expression levels after stimulation with recombinant LIGHT [216].

\subsection{Vasoconstriction}

The major vasoconstrictors released by platelets and elevated in PH patients' lungs are TXA-2 and serotonin [26, 188] (Figure 5). Because activated platelets also reduce endothelial $\mathrm{NO}$ and $\mathrm{PGI}_{2}$ production, they exacerbate the imbalances between vasodilators and vasoconstrictors, promoting vasoconstriction.

There is also evidence that tetrahydrobiopterin (BH4), a cofactor and regulator of eNOS function, is produced by platelets [217]. Mice deficient in BH4 showed increased susceptibility to hypoxia-induced $\mathrm{PH}$, while BH4 supplementation reduced vascular tone and remodelling, preventing disease development [218]. Decreased BH4 production due to platelet dysfunction may therefore contribute to impaired NO production and vasoconstriction.

\subsection{Platelet Microparticles}

Microparticles (MPs) are vesicle fragments (0.1-1 $\mu \mathrm{m}$ in size) derived from plasma membranes of many cell types, usually upon cellular activation or stress, such as apoptosis [219]. Increased platelet MPs (PMPs) levels have been found in various types of PH, compared with healthy controls [220], and their membranes were shown to be 50 to 100 times more pro-coagulant than activated platelets' surfaces [221]. Indeed, increased TF and CD40L expression were found on PMP surfaces in PAH patients, who also displayed increased phosphatidylserine-positive MPs in their Pas [222]. PMPs were shown to regulate vascular tone through TXA-2 production [223], induce in vitro vascular SMCs proliferation [224], as well as VEGF- and PDGF-mediated in vitro and in vivo angiogenesis in a rat aortic ring model [225] (Figure 5). Additionally, incubation of rat PAECs with PMPs from hypoxic PH animals reduced endothelial NO production and increased oxidative stress, while in vivo injections of those PMPs impaired endothelium-dependent relaxation in rat Pas [226]. In PAH patients, PMPs displayed elevated CD39 nucleotidase activity [227], which may promote vasoconstriction and platelet activation through increased ADP production.

PMPs have also been shown to induce endothelial production of IL-1 $\beta$, IL-6, and TNF $\alpha$, as well as ICAM-1 expression [228], indicating that PMPs may promote further platelet aggregation and local inflammation. Interestingly, PMPs shedding was found to be induced by shear stress, with evidence of increased PMPs levels in patients with severe aortic valve stenosis [229]. This could be relevant in conditions of increased shear stress and flow disturbances caused by arterial luminal narrowing and/or thrombotic occlusion in $\mathrm{PH}$. 


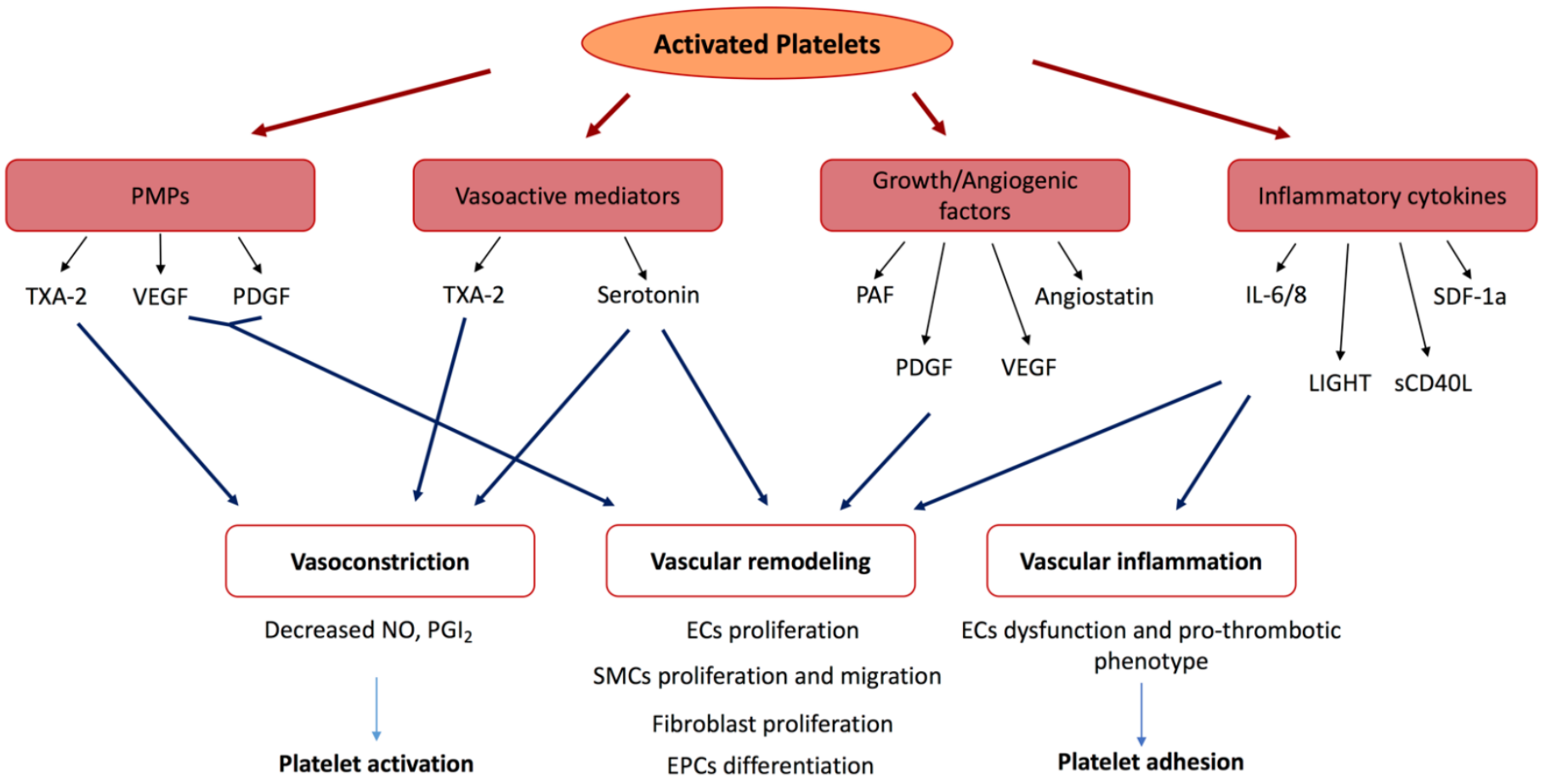

Figure 5. The contribution of platelet-derived factors to $\mathrm{PH}$ pathobiology

This figure summarises the contribution of platelet-derived factors to vasoconstriction, vascular remodelling and inflammation in pulmonary hypertension $(\mathrm{PH})$. Vasoactive mediators, growth and angiogenic factors, inflammatory cytokines and platelet-derived microparticles (PMPs) are released upon platelet activation. All these factors induce endothelial dysfunction, leading to imbalances in nitric oxide $(\mathrm{NO})$ and prostacyclin $\left(\mathrm{PGI}_{2}\right)$ production, and the switch towards an endothelial pro-thrombotic phenotype, which enhance platelet adhesion, activation and aggregation. This in turn causes further release of vasoactive factors from platelet, creating a vicious cycle of vascular remodelling and platelet activation. Many of the growth and angiogenic factors released by platelets promote endothelial cells (ECs) and fibroblast proliferation, smooth muscle cells (SMCs) proliferation and migration, as well as endothelial progenitor cells (EPCs) differentiation, which are major features of the vascular remodelling observed in PH. (IL-6/8: interleukin6/8; LIGHT: lymphotoxin-like inducible protein that competes with glycoprotein D for Herpesvirus entry mediator on T lymphocytes; PAF: platelet activating factor; PDGF: platelet-derived growth factor; sCD40L: soluble CD40 ligand; SDF-1a: stromal-derived factor-1a; TXA-2: thromboxane A-2; VEGF: vascular endothelial growth factor)

\section{Targeting Platelets in Pulmonary Hypertension Treatment}

Most therapeutic strategies in PAH have been focused on targeting the endothelin, NO and prostacyclin pathways [36]. Available drug classes include prostacyclin analogues, endothelin receptors antagonists (ERAs), and phosphodiesterase (PDE)-5 inhibitors [36]. PH due to lung disease and/or hypoxia, and CTEPH may be treated with PAH-approved drugs under specific conditions, but there are no randomised controlled trials supporting the use of $\mathrm{PAH}$ drugs in other forms of $\mathrm{PH}[36]$.

Current therapies successfully target vasoconstriction, but have a modest effect on vascular remodelling. Mortality rate in $\mathrm{PH}$ is high (>20\% within 1 year of diagnosis in high risk patients) [230], and novel, more effective and better targeted therapies are needed. As previously described, platelets show strong links with $\mathrm{PH}$ pathobiology, providing a rationale for the use of anticoagulation or antiplatelet drugs in disease therapy. This section will describe the therapeutic potential of new anti-platelet drugs and comment on beneficial, anti-thrombotic effects of current PH treatments.

\subsection{Anticoagulation and Anti-platelet Drugs}

Most recent treatment guidelines recommend warfarin for IPAH, HPAH and anorexigen-induced PAH, and for CTEPH patients, even after PTE [36]. However, the main evidence is derived from observational and registry studies [6, 231-233], and there is an urgent need for randomised controlled trials specifically evaluating the benefits of anticoagulants in PAH and other forms of PH. In the SERAPHIN trial, which assessed the therapeutic effects of a novel ERA, macitentan, in concomitance with other treatments, no significant difference in mortality and morbidity was found between the placebo and warfarin-treated patients [36]. In the COMPERA registry, anticoagulation use was associated with a $21 \%$ increase in IPAH patient survival [6]. A recent meta-analysis, which included 12 non- 
randomised studies, demonstrated that anticoagulation therapy significantly reduced mortality in IPAH patients, but increased mortality in scleroderma-associated PAH patients [234], indicating that anticoagulation should be carefully tailored to the PAH subtype.

Anti-platelet therapy has also been assessed in PAH. A randomised controlled trial of 19 IPAH patients found that aspirin and clopidogrel reduced platelet aggregation, with aspirin but not clopidogrel reducing urinary TXA-2 metabolites levels, as well as the TXA-2:PGI ratio [235]. Another controlled study of aspirin and simvastatin in 92 PAH patients found reduced TXA-2 production, but no effects on platelet aggregation and 6-minutes walking distance test (6MWDT) results compared to controls [236]. Interestingly, aspirin reduced PAP, RV hypertrophy and improved survival in MCT rat models, which was associated with decreased plasma levels of platelet-derived serotonin [237].

The efficacy of anti-platelet therapies therefore remains inconclusive. Other drugs interfering with plateletendothelial interactions, such as monoclonal antibodies against the VWF A1 domain [238] or platelet GPIIb/IIIa [239] may be of relevance in PH treatment.

\subsection{Prostacyclin Analogues}

As previously mentioned, $\mathrm{PGI}_{2}$ is a key inhibitor of platelet aggregation[104], beside its vasodilatory and antiproliferative effects [102, 103]. Many $\mathrm{PGI}_{2}$ analogues are used in PAH treatment, including epoprostenol or iloprost [36]. Iloprost was shown to directly inhibit agonist-induced platelet activation [240], while continuous epoprostenol infusion increased TM, decreased P-selectin levels [241], and normalised platelet aggregation [242] in primary and secondary PH patients. Epoprostenol was also shown to decrease LIGHT serum levels in PAH patients [216], and inhibit PMPs formation in whole blood [243]. These data suggest that the benefits of $\mathrm{PGI}_{2}$ therapy in $\mathrm{PH}$ patients could partially be explained by their inhibitory action on platelets.

\subsection{Phosphodiesterase Inhibitors}

PDE-5 is one of the most active PDEs in the pulmonary vasculature, and promotes vasoconstriction by inhibiting cGMP in the NO/cGMP pathway [244]. Sildenafil, vardenafil and tadalafil are all PDE-5is approved for the treatment of erectile dysfunction, and have been shown to induce significant pulmonary vasodilation in PAH patients [245]. Sildenafil reduced platelet activation in sickle-cell disease-associated PAH [246], while vardenafil blocked platelet $\mathrm{Ca}^{2+}$ channels, reducing $\mathrm{Ca}^{2+}$ mobilisation and influx in thrombin-stimulated, rabbit washed platelets [247].

Milirone is a PDE-3 inhibitor used for PPHN[248] and post-operative PH [249] treatment. While it has been shown to inhibit platelet activation [250], it also has a side effect of thrombocytopenia [251]. It currently remains unclear whether the benefits of milirone are due to its antiplatelet or vasodilatory actions.

\subsection{PDGFR Inhibitors}

Imatinib is a multi-kinase (including PDGFR tyrosine kinase) inhibitor, which has been shown to reverse vascular remodelling in MCT rats and chronic hypoxia mice [175]. When combined with other PAH-approved drugs, including epoprostenol or sildenafil, imatinib improved the haemodynamics and functional capacities of severe PAH patients [252]. Sorafenib is another PDGFR inhibitor, demonstrated to prevent vascular remodelling and improve cardiopulmonary functions in experimental PH[165]. PDGFR inhibitors may therefore exert their beneficial actions by counteracting the mitogenic [171] and chemoattractant [172] effects of platelet-derived PDGF on PASMCs.

\subsection{Serotonin Antagonists}

Serotonin transport and signalling could be a promising therapeutic target in PH. Indeed, inhibition of the 5HT1BR attenuated hypoxia-induced PH in rat models [253], while PH patients receiving selective serotonin reuptake inhibitors (SSRIs) had a decreased mortality compared to those not receiving SSRIs [254]. Another study demonstrated that SERT inhibition decreased serotonin-induced proliferation of PASMC from IPAH patients in vitro by interfering with the ROCK signalling pathway [195]. A selective 5-HT-2BR antagonist (PRX-8066) was assessed in a randomised controlled trial of 72 COPD-associated PAH patients (trial no. NCT00677872), but only modest reductions in systolic PAP were observed, and the trial was discontinued. After encouraging pre-clinical results in MCT rat models [255], Terguride, a dual 5-HT-2A/BRs antagonist, was also tested in IPAH and PAH with connective tissue disease patients, but no improvements in haemodynamics, 6MWDT or time to clinical worsening were observed [256]. Only patients on background ERAs therapy showed improvements in PVR [256]. Interestingly, SERT, but not 5-HT receptors antagonists, limited PH patients-derived PASMCs growth responses to serotonin [192], suggesting that SERT may be a better therapeutic target than 5HTRs.

\subsection{Other Therapies}

$\mathrm{NO}$ is a potent inhibitor of platelet activation and aggregation [257], which explains the benefits of inhaled NO 
administration in acute PH after cardiac surgery [258] and in PPHN [259]. Inhibition of TXA-2 synthesis with furegrelate sodium preserved vascular integrity and lowered PVR in chronic hypoxia piglets [260], and a recent study demonstrated that a novel antagonist of the thromboxane prostanoid receptor, NTP42, reduced mPAP, RV systolic pressure, vascular remodelling, inflammation and fibrosis in MCT-induced PAH rat models [261].

Determining whether platelet dysfunction and aggregation are a cause or consequence of PH pathobiology constitutes a challenge. While platelets are appealing therapeutic targets, their effects on the vasculature are complex, and a better understanding of how platelet content and degranulation are modulated is required. Some factors may be protective in $\mathrm{PH}$, such as soluble tumour necrosis factor-like weak inducer of apoptosis (sTWEAK), whose reduced platelet storage levels are associated with worse prognosis in PAH [262]. Therefore, simply inhibiting platelet activity may not be the solution in the inflammatory context of $\mathrm{PH}$, and therapeutic strategies must be carefully designed.

\section{Investigating the Role of Platelets in Pulmonary Hypertension: Current Models}

\subsection{In Vivo Models}

Intravital microscopy has been used since the $19^{\text {th }}$ century [76], and the latest advances in the field have allowed highly precise, real-time in vivo monitoring of platelet adhesion and thrombus formation [263]. Current techniques mostly use murine systems, and involve inducing platelet aggregation via mechanical [264], electrical laser [265], chemical $\left(\mathrm{FeCl}_{3}\right)$ [266] or photochemical [267] injury to the vascular wall. Other methods using lipopolysaccharide [268] or calcium ionophores [123] have been used to promote platelet-endothelial interactions, but these usually do not result in full thrombogenesis.

These methods all cause thrombus formation through different mechanisms, and should therefore be chosen according to the experimental question to be addressed. For instance, while $\mathrm{FeCl}_{3}$-induced injury involves endothelial denudation and subendothelial platelet adhesion [266], photochemical techniques do not deteriorate the endothelium, and thrombus formation is initiated by platelet-endothelial interactions [267].

Although useful for studying the mechanisms involved in platelet aggregation and thrombogenesis, these models may introduce artefacts and deviate from physiological relevance. To overcome this, mice transgenic for genes involved in haemostasis and fibrinolysis have been developed [269], but the major differences between human and mice vascular systems make murine findings challenging to translate into clinical practice [270].

Animal models of CTEPH have been developed since the 1990s, although none of them are representative of all human CTEPH features [271, 272]. One piglet model of CTEPH, developed by primary left PA ligation via sternotomy, followed by weekly transcatheter embolizations of Histoacryl into the right lower lobe for 5 weeks, was able to reconstruct most aspects of the disease, notably its dual pulmonary vascular bed component [273]. However, no model currently replicates the impaired fibrinolysis characteristic of CTEPH.

Many other models of PH exist, with MCT-[274], chronic hypoxia-[275] and Sugen-induced PH rats [166] and mice [276] being the most commonly used. Rats are usually better than mice in reflecting the degree of vascular remodelling observed in PAH patients [166, 274-276], although none of the existing models can accurately recreate all the features of human PH.

\subsection{In Vitro Models}

Many standardised in vitro assays exist to evaluate platelet function and aggregation, including platelet aggregometry [141, 151] and flow cytometry [142]. Platelet aggregometry involves exposing platelets to agonists (eg ADP, thrombin or TXA-2) in vitro, and has been used to identify platelet function abnormalities in CTEPH [141] and PAH [151].

However, considering the importance of haemodynamics and other blood components in thrombus formation, the static and isolated nature of these assays makes them physiologically irrelevant. Additionally, most of them require large amounts of whole blood [141, 142], a major limiting factor in many clinical situations.

Microfluidic devices, where blood or isolated platelets are perfused through microscopic-size channels, address some of these limitations, and their development has boomed over the past decades. First designed 50 years ago [277], these devices have enabled the investigation of many cellular and molecular mechanisms involved in haemostasis and thrombosis in a reproducible manner. Technological advancements have also greatly reduced the blood volumes required for experiments $(<1 \mathrm{~mL})[278,279]$.

Extracellular matrix (for example collagen)-coated devices are one of the simplest models, widely used to simulate thrombotic responses to vascular injury [280], or to evaluate dose-responses to antiplatelet drugs [279]. However, such models do not fully replicate the important dynamics between ECs, platelets and shear stress and therefore poorly correlate with the in vivo observations [263]. More complex, endothelium-lined devices have since been developed 
and used in modelling thrombosis modelled under physiological shear conditions [278, 281]. A wide range of parallel or Y-shaped flow chambers are commercially available, and new software programmes help the design of customised channels. These usually provide a better reconstitution of the in vivo vessel geometries, such as stenosis or branch points, and have been used to model shear gradient-dependent platelet aggregation [105, 155]. More recently, Costa and colleagues [282] have used 3D-printing and computed tomography angiography data to recreate healthy and stenosed blood vessel chambers, lined with human umbilical vein endothelial cells (HUVECs).

Nevertheless, the use of cellular monolayer does not reflect the true dynamic, multi-cellular vascular microenvironment. Organs-on-chips (OOCs) are microfluidic platforms within which one or more living cell population(s) can be cultured simultaneously under flow conditions, aiming to mimic tissue- and organ-level physiological environments [283]. A few models of thrombosis-on-chips have been published, for instance by Jain and colleagues [106], who showed that tissue-tissue interactions between the alveolar epithelium and vascular endothelium were required for lipopolysaccharide-mediated intravascular thrombosis. However, despite the availability of microfluidic arterial wall [284], biomimetic PA models [285], and a recently published PA-on-a-chip model [286] , the role of platelet aggregation in the context of PH pathobiology has not been assessed using OOC technologies.

\section{Conclusion}

Platelets are key players in the pathobiology of $\mathrm{PH}$, through their involvement in thrombosis, vascular remodelling and vasoconstriction. While the true nature of platelets' contribution to this complex, multifactorial disease is not fully understood, the degree of platelet contribution to the disease aetiology is likely to vary among functional classes of $\mathrm{PH}$. Nevertheless, in all forms of PH, endothelial dysfunction, inflammation, $\mathrm{NO} / \mathrm{PGI}_{2}$ reduction, and disturbed flow caused by luminal narrowing, favours a pro-thrombotic environment, leading to platelet aggregation. Activated and aggregated platelets are likely to promote further vascular remodelling and inflammation through the release of vasoactive and inflammatory mediators, worsening the clinical outcome.

While the existing therapies are effective in reducing vasoconstriction, they fail to reverse vascular remodelling. Targeting platelet adhesion, aggregation and activation may be beneficial in PH and therapeutic strategies should be tailored to the individual patient's needs. Despite the advances made in modelling platelet function, more physiologically relevant in vitro systems, utilising patient-derived cells and accounting for both vascular remodelling and the resultant flow disturbances, need to be designed

\section{Funding}

This work was funded by the Imperial College President's PhD scholarships.

\section{Declaration of Competing Interest}

The authors declare that they have no known competing financial interests or personal relationships that could have appeared to influence the work reported in this paper.

\section{Ethical Approval}

The manuscript does not contain experiments on animals and humans; hence ethical permission not required.

\section{References}

[1] Schermuly, R. T., Ghofrani, H. A., Wilkins, M. R., \& Grimminger, F. (2011). Mechanisms of disease: pulmonary arterial hypertension. Nature Reviews Cardiology, 8(8), 443-455. doi:10.1038/nrcardio.2011.87.

[2] Becattini, C., Agnelli, G., Pesavento, R., Silingardi, M., Poggio, R., Taliani, M. R., \& Ageno, W. (2006). Incidence of Chronic Thromboembolic Pulmonary Hypertension after a First Episode of Pulmonary Embolism. Chest, 130(1), $172-175$. doi:10.1378/chest.130.1.172.

[3] Simonneau, G., Gatzoulis, M. A., Adatia, I., Celermajer, D., Denton, C., Ghofrani, A., ... \& Olschewski, H. (2013). Updated clinical classification of pulmonary hypertension. Journal of the American College of Cardiology, 62(25 Supplement), D34D41.

[4] Humbert, M., Sitbon, O., Chaouat, A., Bertocchi, M., Habib, G., Gressin, V., ... \& Dromer, C. (2006). Pulmonary arterial hypertension in France: results from a national registry. American journal of respiratory and critical care medicine, 173(9), 1023-1030.

[5] Badesch, D. B., Raskob, G. E., Elliott, C. G., Krichman, A. M., Farber, H. W., Frost, A. E., ... McGoon, M. D. (2010). Pulmonary Arterial Hypertension. Chest, 137(2), 376-387. doi:10.1378/chest.09-1140.

[6] Olsson, K. M., Delcroix, M., Ghofrani, H. A., Tiede, H., Huscher, D., Speich, R., ... Hoeper, M. M. (2014). Anticoagulation and Survival in Pulmonary Arterial Hypertension. Circulation, 129(1), 57-65. doi:10.1161/circulationaha.113.004526. 
[7] Augoustides, J., \& Ramakrishna, H. (2009). Faculty Opinions recommendation of ACCF/AHA 2009 expert consensus document on pulmonary hypertension a report of the American College of Cardiology Foundation Task Force on Expert Consensus Documents and the American Heart Association developed in collaboration with the American College of Chest Physicians; American Thoracic Society, Inc.; and the Pulmonary Hypertension Association. Faculty Opinions - PostPublication Peer Review of the Biomedical Literature. doi:10.3410/f.1164913.625748.

[8] Thabut, G., Dauriat, G., Stern, J. B., Logeart, D., Levy, A., Marrash-Chahla, R., \& Mal, H. (2005). Pulmonary Hemodynamics in Advanced COPD Candidates for Lung Volume Reduction Surgery or Lung Transplantation. Chest, 127(5), $1531-1536$. doi:10.1378/chest.127.5.1531.

[9] Miller, W. L., Grill, D. E., \& Borlaug, B. A. (2013). Clinical Features, Hemodynamics, and Outcomes of Pulmonary Hypertension Due to Chronic Heart Failure With Reduced Ejection Fraction. JACC: Heart Failure, 1(4), $290-299$. doi:10.1016/j.jchf.2013.05.001.

[10] Bursi, F., McNallan, S. M., Redfield, M. M., Nkomo, V. T., Lam, C. S., Weston, S. A., ... \& Roger, V. L. (2012). Pulmonary pressures and death in heart failure: a community study. Journal of the American College of Cardiology, 59(3), 222-231.

[11] Thienemann, F., Dzudie, A., Mocumbi, A. O., Blauwet, L., Sani, M. U., Karaye, K. M., ... Sliwa, K. (2016). The causes, treatment, and outcome of pulmonary hypertension in Africa: Insights from the Pan African Pulmonary Hypertension Cohort (PAPUCO) Registry. International Journal of Cardiology, 221, 205-211. doi:10.1016/j.ijcard.2016.06.242.

[12] E. Mahmud et al., (2018). Chronic Thromboembolic Pulmonary Hypertension, J. Am. Coll. Cardiol., 71(21), $2468-2486$.

[13] Gall, H., Hoeper, M. M., Richter, M. J., Cacheris, W., Hinzmann, B., \& Mayer, E. (2017). An epidemiological analysis of the burden of chronic thromboembolic pulmonary hypertension in the USA, Europe and Japan. European Respiratory Review, 26(143), 160121. doi:10.1183/16000617.0121-2016.

[14] Ende-Verhaar, Y. M., Cannegieter, S. C., Vonk Noordegraaf, A., Delcroix, M., Pruszczyk, P., Mairuhu, A. T. A., ... Klok, F. A. (2017). Incidence of chronic thromboembolic pulmonary hypertension after acute pulmonary embolism: a contemporary view of the published literature. European Respiratory Journal, 49(2), 1601792. doi:10.1183/13993003.01792-2016.

[15] Hoeper, M. M., Humbert, M., Souza, R., Idrees, M., Kawut, S. M., Sliwa-Hahnle, K., .. Gibbs, J. S. R. (2016). A global view of pulmonary hypertension. The Lancet Respiratory Medicine, 4(4), 306-322. doi:10.1016/s2213-2600(15)00543-3.

[16] Heath, D., \& EDWARDS, J. E. (1958). The pathology of hypertensive pulmonary vascular disease: a description of six grades of structural changes in the pulmonary arteries with special reference to congenital cardiac septal defects. Circulation, 18(4), 533-547.

[17] YI, E. S., KIM, H., AHN, H., STROTHER, J., MORRIS, T., MASLIAH, E., ... FRIEDMAN, P. J. (2000). Distribution of Obstructive Intimal Lesions and Their Cellular Phenotypes in Chronic Pulmonary Hypertension. American Journal of Respiratory and Critical Care Medicine, 162(4), 1577-1586. doi:10.1164/ajrccm.162.4.9912131.

[18] Zaiman, A., Fijalkowska, I., Hassoun, P. M., \& Tuder, R. M. (2005). One Hundred Years of Research in the Pathogenesis of Pulmonary Hypertension. American Journal of Respiratory Cell and Molecular Biology, 33(5), $425-431$. doi: $10.1165 / \mathrm{rcmb} . \mathrm{f3} 307$.

[19] Wilson, J. L., Yu, J., Taylor, L., \& Polgar, P. (2015). Hyperplastic Growth of Pulmonary Artery Smooth Muscle Cells from Subjects with Pulmonary Arterial Hypertension Is Activated through JNK and p38 MAPK. PLOS ONE, 10(4), e0123662. doi:10.1371/journal.pone.0123662.

[20] Eddahibi, S., Humbert, M., Fadel, E., Raffestin, B., Darmon, M., Capron, F., ... Adnot, S. (2001). Serotonin transporter overexpression is responsible for pulmonary artery smooth muscle hyperplasia in primary pulmonary hypertension. Journal of Clinical Investigation, 108(8), 1141-1150. doi:10.1172/jci200112805.

[21] Li, X., Zhang, X., Leathers, R., Makino, A., Huang, C., Parsa, P., ... Thistlethwaite, P. A. (2009). Notch3 signaling promotes the development of pulmonary arterial hypertension. Nature Medicine, 15(11), 1289-1297. doi:10.1038/nm.2021.

[22] Yu, Y., Fantozzi, I., Remillard, C. V., Landsberg, J. W., Kunichika, N., Platoshyn, O., ... Yuan, J. X.-J. (2004). Enhanced expression of transient receptor potential channels in idiopathic pulmonary arterial hypertension. Proceedings of the National Academy of Sciences, 101(38), 13861-13866. doi:10.1073/pnas.0405908101.

[23] Cheng, X., Wang, Y., \& Du, L. (2019). Epigenetic Modulation in the Initiation and Progression of Pulmonary Hypertension. Hypertension, 74(4), 733-739. doi:10.1161/hypertensionaha.119.13458.

[24] Giaid, A., Yanagisawa, M., Langleben, D., Michel, R. P., Levy, R., Shennib, H., ... Stewart, D. J. (1993). Expression of Endothelin-1 in the Lungs of Patients with Pulmonary Hypertension. New England Journal of Medicine, 328(24), $1732-1739$. doi:10.1056/nejm199306173282402.

[25] Giaid, A., \& Saleh, D. (1995). Reduced Expression of Endothelial Nitric Oxide Synthase in the Lungs of Patients with Pulmonary Hypertension. New England Journal of Medicine, 333(4), 214-221. doi:10.1056/nejm199507273330403. 
[26] Christman, B. W., McPherson, C. D., Newman, J. H., King, G. A., Bernard, G. R., Groves, B. M., \& Loyd, J. E. (1992). An Imbalance between the Excretion of Thromboxane and Prostacyclin Metabolites in Pulmonary Hypertension. New England Journal of Medicine, 327(2), 70-75. doi:10.1056/nejm199207093270202.

[27] Masri, F. A., Xu, W., Comhair, S. A. A., Asosingh, K., Koo, M., Vasanji, A., ... Erzurum, S. C. (2007). Hyperproliferative apoptosis-resistant endothelial cells in idiopathic pulmonary arterial hypertension. American Journal of Physiology-Lung Cellular and Molecular Physiology, 293(3), L548-L554. doi:10.1152/ajplung.00428.2006.

[28] Xu, W., Koeck, T., Lara, A. R., Neumann, D., DiFilippo, F. P., Koo, M., .. \& Dweik, R. A. (2007). Alterations of cellular bioenergetics in pulmonary artery endothelial cells. Proceedings of the National Academy of Sciences, 104(4), 1342-1347.

[29] Huertas, A., Guignabert, C., Barberà, J. A., Bärtsch, P., Bhattacharya, J., Bhattacharya, S., ... Wilkins, M. R. (2018). Pulmonary vascular endothelium: the orchestra conductor in respiratory diseases. European Respiratory Journal, 51(4), 1700745. doi:10.1183/13993003.00745-2017.

[30] Soon, E., Holmes, A. M., Treacy, C. M., Doughty, N. J., Southgate, L., Machado, R. D., ... Morrell, N. W. (2010). Elevated Levels of Inflammatory Cytokines Predict Survival in Idiopathic and Familial Pulmonary Arterial Hypertension. Circulation, 122(9), 920-927. doi:10.1161/circulationaha.109.933762.

[31] Tuder, R. M., Groves, B., Badesch, D. B., \& Voelkel, N. F. (1994). Exuberant endothelial cell growth and elements of inflammation are present in plexiform lesions of pulmonary hypertension. The American journal of pathology, 144(2), 275.

[32] Kazimierczyk, R., \& Kamiński, K. (2018). The role of platelets in the development and progression of pulmonary arterial hypertension. Advances in Medical Sciences, 63(2), 312-316. doi:10.1016/j.advms.2018.04.013.

[33] Bjornsson, J., \& Edwards, W. D. (1985). Primary Pulmonary Hypertension: A Histopathologic Study of 80 Cases. Mayo Clinic Proceedings, 60(1), 16-25. doi:10.1016/s0025-6196(12)65277-x.

[34] Humbert, M., Guignabert, C., Bonnet, S., Dorfmüller, P., Klinger, J. R., Nicolls, M. R., ... Rabinovitch, M. (2019). Pathology and pathobiology of pulmonary hypertension: state of the art and research perspectives. European Respiratory Journal, 53(1), 1801887. doi:10.1183/13993003.01887-2018.

[35] Hoeper, M. M., Bogaard, H. J., Condliffe, R., Frantz, R., Khanna, D., Kurzyna, M., ... \& Wilkins, M. R. (2013). Definitions and diagnosis of pulmonary hypertension. Journal of the American College of Cardiology, 62(25 Supplement), D42-D50.

[36] Galiè, N., Humbert, M., Vachiery, J. L., Gibbs, S., Lang, I., Torbicki, A., .. \& Ghofrani, A. (2016). 2015 ESC/ERS guidelines for the diagnosis and treatment of pulmonary hypertension: the Joint Task Force for the Diagnosis and Treatment of Pulmonary Hypertension of the European Society of Cardiology (ESC) and the European Respiratory Society (ERS): endorsed by: Association for European Paediatric and Congenital Cardiology (AEPC), International Society for Heart and Lung Transplantation (ISHLT). European heart journal, 37(1), 67-119.

[37] McLaughlin, V. V., Hoeper, M. M., Channick, R. N., Chin, K. M., Delcroix, M., Gaine, S., ... Galiè, N. (2018). Pulmonary Arterial Hypertension-Related Morbidity Is Prognostic for Mortality. Journal of the American College of Cardiology, 71(7), 752-763. doi:10.1016/j.jacc.2017.12.010.

[38] Gilmour, J. R., \& Evans, W. (1946). Primary pulmonary hypertension. The Journal of Pathology and Bacteriology, 58(4), 687697. doi:10.1002/path.1700580410.

[39] Le Cras, T. D., Hardie, W. D., Fagan, K., Whitsett, J. A., \& Korfhagen, T. R. (2003). Disrupted pulmonary vascular development and pulmonary hypertension in transgenic mice overexpressing transforming growth factor- $\alpha$. American Journal of Physiology-Lung Cellular and Molecular Physiology, 285(5), L1046-L1054. doi:10.1152/ajplung.00045.2003.

[40] Geiger, R., Berger, R. M. F., Hess, J., Bogers, A. J. J. C., Sharma, H. S., \& Mooi, W. J. (2000). Enhanced expression of vascular endothelial growth factor in pulmonary plexogenic arteriopathy due to congenital heart disease. The Journal of pathology, 191(2), 202-207. doi:10.1002/(SICI)1096-9896(200006)191:2<202::AID-PATH608>3.0.CO;2-D.

[41] Ranchoux, B., Antigny, F., Rucker-Martin, C., Hautefort, A., Péchoux, C., Bogaard, H. J., ... Perros, F. (2015). Endothelial-toMesenchymal Transition in Pulmonary Hypertension. Circulation, 131(11), $1006-1018$. doi:10.1161/circulationaha.114.008750.

[42] Zhou, C., Townsley, M. I., Alexeyev, M., Voelkel, N. F., \& Stevens, T. (2016). Endothelial hyperpermeability in severe pulmonary arterial hypertension: role of store-operated calcium entry. American Journal of Physiology-Lung Cellular and Molecular Physiology, 311(3), L560-L569. doi:10.1152/ajplung.00057.2016.

[43] Frid, M. G., Kale, V. A., \& Stenmark, K. R. (2002). Mature Vascular Endothelium Can Give Rise to Smooth Muscle Cells via Endothelial-Mesenchymal Transdifferentiation. Circulation $\quad$ Research, $1189-1196$. doi:10.1161/01.res.0000021432.70309.28. 
[44] Frid, M. G., Brunetti, J. A., Burke, D. L., Carpenter, T. C., Davie, N. J., Reeves, J. T., ... Stenmark, K. R. (2006). HypoxiaInduced Pulmonary Vascular Remodeling Requires Recruitment of Circulating Mesenchymal Precursors of a Monocyte/Macrophage Lineage. The American Journal of Pathology, 168(2), 659-669. doi:10.2353/ajpath.2006.050599.

[45] Davie, N. J., Crossno, J. T., Frid, M. G., Hofmeister, S. E., Reeves, J. T., Hyde, D. M., ... Stenmark, K. R. (2004). Hypoxiainduced pulmonary artery adventitial remodeling and neovascularization: contribution of progenitor cells. American Journal of Physiology-Lung Cellular and Molecular Physiology, 286(4), L668-L678. doi:10.1152/ajplung.00108.2003.

[46] Wang, X.-X., Zhang, F.-R., Shang, Y.-P., Zhu, J.-H., Xie, X.-D., Tao, Q.-M., .. Chen, J.-Z. (2007). Transplantation of Autologous Endothelial Progenitor Cells May Be Beneficial in Patients With Idiopathic Pulmonary Arterial Hypertension. Journal of the American College of Cardiology, 49(14), 1566-1571. doi:10.1016/j.jacc.2006.12.037.

[47] Zhao, Y. D., Courtman, D. W., Deng, Y., Kugathasan, L., Zhang, Q., \& Stewart, D. J. (2005). Rescue of MonocrotalineInduced Pulmonary Arterial Hypertension Using Bone Marrow-Derived Endothelial-Like Progenitor Cells. Circulation Research, 96(4), 442-450. doi:10.1161/01.res.0000157672.70560.7b.

[48] Southgate, L., Machado, R. D., Gräf, S., \& Morrell, N. W. (2019). Molecular genetic framework underlying pulmonary arterial hypertension. Nature Reviews Cardiology, 17(2), 85-95. doi:10.1038/s41569-019-0242-x.

[49] Atkinson, C., Stewart, S., Upton, P. D., Machado, R., Thomson, J. R., Trembath, R. C., \& Morrell, N. W. (2002). Primary Pulmonary Hypertension Is Associated With Reduced Pulmonary Vascular Expression of Type II Bone Morphogenetic Protein Receptor. Circulation, 105(14), 1672-1678. doi:10.1161/01.cir.0000012754.72951.3d.

[50] Gomez-Puerto, M. C., Zuijen, I., Huang, C. J., Szulcek, R., Pan, X., Dinther, M. A., “. ten Dijke, P. (2019). Autophagy contributes to BMP type 2 receptor degradation and development of pulmonary arterial hypertension. The Journal of Pathology, 249(3), 356 - 367. doi:10.1002/path.5322.

[51] Hong, K.-H., Lee, Y. J., Lee, E., Park, S. O., Han, C., Beppu, H., ... Oh, S. P. (2008). Genetic Ablation of the Bmpr2 Gene in Pulmonary Endothelium Is Sufficient to Predispose to Pulmonary Arterial Hypertension. Circulation, 118(7), 722-730. doi:10.1161/circulationaha.107.736801.

[52] J. H. Newman et al., (2001). Mutation in the Gene for Bone Morphogenetic Protein Receptor II as a Cause of Primary Pulmonary Hypertension in a Large Kindred. New England Journal of Medicine, 345(20), $1506-1506$. doi:10.1056/nejm200111153452022.

[53] Mehra, P., Mehta, V., Sukhija, R., Sinha, A. K., Gupta, M., Girish, M. P., \& Aronow, W. S. (2019). Pulmonary hypertension in left heart disease. Archives of medical science: AMS, 15(1), 262-273.

[54] Opitz, I., \& Kirschner, M. (2019). Molecular Research in Chronic Thromboembolic Pulmonary Hypertension. International Journal of Molecular Sciences, 20(3), 784. doi:10.3390/ijms20030784.

[55] Du, L., Sullivan, C. C., Chu, D., Cho, A. J., Kido, M., Wolf, P. L., ... Thistlethwaite, P. A. (2003). Signaling Molecules in Nonfamilial Pulmonary Hypertension. New England Journal of Medicine, 348(6), 500-509. doi:10.1056/nejmoa021650.

[56] Thompson, A. A. R., \& Lawrie, A. (2017). Targeting Vascular Remodeling to Treat Pulmonary Arterial Hypertension. Trends in Molecular Medicine, 23(1), 31-45. doi:10.1016/j.molmed.2016.11.005.

[57] Inglesby, T. V., Singer, J. W., \& Gordon, D. S. (1973). Abnormal fibrinolysis in familial pulmonary hypertension. The American Journal of Medicine, 55(1), 5-14. doi:10.1016/0002-9343(73)90144-7.

[58] Pietra, G. G., Edwards, W. D., Kay, J. M., Rich, S., Kernis, J., Schloo, B., ... Detre, K. M. (1989). Histopathology of primary pulmonary hypertension. A qualitative and quantitative study of pulmonary blood vessels from 58 patients in the National Heart, Lung, and Blood Institute, Primary Pulmonary Hypertension Registry. Circulation, 80(5), 1198-1206. doi:10.1161/01.cir.80.5.1198.

[59] Moser, K. M., Fedullo, P. F., Finkbeiner, W. E., \& Golden, J. (1995). Do Patients With Primary Pulmonary Hypertension Develop Extensive Central Thrombi? Circulation, 91(3), 741-745. doi:10.1161/01.cir.91.3.741.

[60] Blauwet, L. A., Edwards, W. D., Tazelaar, H. D., \& McGregor, C. G. . (2003). Surgical pathology of pulmonary thromboendarterectomy: a study of 54 cases from 1990 to 2001. Human Pathology, 34(12), 1290-1298. doi:10.1016/j.humpath.2003.07.003.

[61] Moser, K. M., Auger, W. R., \& Fedullo, P. F. (1990). Chronic major-vessel thromboembolic pulmonary hypertension. Circulation, 81(6), 1735-1743. doi:10.1161/01.cir.81.6.1735.

[62] Riedel, M., Stanek, V., Widimsky, J., \& Prerovsky, I. (1982). Longterm Follow-up of Patients with Pulmonary Thromboembolism. Chest, 81(2), 151-158. doi:10.1378/chest.81.2.151.

[63] Sacks, R. S., Remillard, C. V., Agange, N., Auger, W. R., Thistlethwaite, P. A., \& Yuan, J. X.-J. (2006). Molecular Biology of Chronic Thromboembolic Pulmonary Hypertension. Seminars in Thoracic and Cardiovascular Surgery, 18(3), $265-276$. doi:10.1053/j.semtcvs.2006.09.004. 
[64] Pepke-Zaba, J., Delcroix, M., Lang, I., Mayer, E., Jansa, P., Ambroz, D., ... Simonneau, G. (2011). Chronic Thromboembolic Pulmonary Hypertension (CTEPH). Circulation, 124(18), 1973-1981. doi:10.1161/circulationaha.110.015008.

[65] Wolf, M., Boyer-Neumann, C., Parent, F., Eschwege, V., Jaillet, H., Meyer, D., \& Simonneau, G. (2000). Thrombotic risk factors in pulmonary hypertension. European Respiratory Journal, 15(2), 395-399.

[66] Bonderman, D., Turecek, P., Jakowitsch, J., Weltermann, A., Adlbrecht, C., Schneider, B., ... Lang, I. (2003). High prevalence of elevated clotting factor VIII in chronic thromboembolic pulmonary hypertension. Thrombosis and Haemostasis, 90(09), 372-376. doi:10.1160/th03-02-0067.

[67] Morris, T. A., Marsh, J. J., Chiles, P. G., Auger, W. R., Fedullo, P. F., \& Woods, V. L. (2006). Fibrin Derived from Patients with Chronic Thromboembolic Pulmonary Hypertension Is Resistant to Lysis. American Journal of Respiratory and Critical Care Medicine, 173(11), 1270-1275. doi:10.1164/rccm.200506-916oc.

[68] Suntharalingam, J., Goldsmith, K., van Marion, V., Long, L., Treacy, C. M., Dudbridge, F., ... Morrell, N. W. (2008). Fibrinogen A Thr312Ala polymorphism is associated with chronic thromboembolic pulmonary hypertension. European Respiratory Journal, 31(4), 736-741. doi:10.1183/09031936.00055107.

[69] Bonderman, D., Jakowitsch, J., Adlbrecht, C., Schemper, M., Kyrle, P., Schönauer, V., ... Lang, I. (2005). Medical conditions increasing the risk of chronic thromboembolic pulmonary hypertension. Thrombosis and Haemostasis, 93(03), 512-516. doi:10.1160/th04-10-0657.

[70] Zabini, D., Heinemann, A., Foris, V., Nagaraj, C., Nierlich, P., Bálint, Z., ... Olschewski, A. (2014). Comprehensive analysis of inflammatory markers in chronic thromboembolic pulmonary hypertension patients. European Respiratory Journal, 44(4), 951-962. doi:10.1183/09031936.00145013.

[71] Azarian, R., Wartski, M., Collignon, M. A., \& Parent, F. (1997). Lung perfusion scans and hemodynamics in acute and chronic pulmonary embolism. The Journal of nuclear medicine, 38(6), 980.

[72] Moser, K. M., \& Bioor, C. M. (1993). Pulmonary Vascular Lesions Occurring in Patients with Chronic Major Vessel Thromboembolic Pulmonary Hypertension. Chest, 103(3), 685-692. doi:10.1378/chest.103.3.685.

[73] Sakao, S., Hao, H., Tanabe, N., Kasahara, Y., Kurosu, K., \& Tatsumi, K. (2011). Endothelial-like cells in chronic thromboembolic pulmonary hypertension: crosstalk with myofibroblast-like cells. Respiratory Research, 12(1). doi:10.1186/1465-9921-12-109.

[74] Firth, A. L., Yao, W., Ogawa, A., Madani, M. M., Lin, G. Y., \& Yuan, J. X.-J. (2010). Multipotent mesenchymal progenitor cells are present in endarterectomized tissues from patients with chronic thromboembolic pulmonary hypertension. American Journal of Physiology-Cell Physiology, 298(5), C1217-C1225. doi:10.1152/ajpcell.00416.2009.

[75] Egermayer, P., \& Peacock, A. J. (2000). Is pulmonary embolism a common cause of chronic pulmonary hypertension? Limitations of the embolic hypothesis. European Respiratory Journal, 15(3), 440-448. doi:10.1034/j.1399-3003.2000.15.03.x.

[76] Bizzozero, J. (1882). Ueber einen neuen Formbestandtheil des Blutes und dessen Rolle bei der Thrombose und der Blutgerinnung. Archiv Für Pathologische Anatomie Und Physiologie Und Für Klinische Medicin, 90(2), $261-332$. doi:10.1007/bf01931360.

[77] Wright, J. H. (1906). The Origin and Nature of the Blood Plates. The Boston Medical and Surgical Journal, 154(23), 643-645. doi:10.1056/nejm190606071542301.

[78] Ghoshal, K., \& Bhattacharyya, M. (2014). Overview of Platelet Physiology: Its Hemostatic and Nonhemostatic Role in Disease Pathogenesis. The Scientific World Journal, 1-16. doi:10.1155/2014/781857.

[79] Trowbridge, E. A., Martin, J. F., Slater, D. N., Kishk, Y. T., Warren, C. W., Harley, P. J., \& Woodcock, B. (1984). The origin of platelet count and volume. Clinical physics and physiological measurement: an official journal of the Hospital Physicists' Association, Deutsche Gesellschaft fur Medizinische Physik and the European Federation of Organisations for Medical Physics, 5(3), 145-170.

[80] Gernsheimer, T., Stratton, J., Ballem, P. J., \& Slichter, S. J. (1989). Mechanisms of Response to Treatment in Autoimmune Thrombocytopenic Purpura. New England Journal of Medicine, 320(15), 974-980. doi:10.1056/nejm198904133201505.

[81] Versteeg, H. H., Heemskerk, J. W. M., Levi, M., \& Reitsma, P. H. (2013). New Fundamentals in Hemostasis. Physiological Reviews, 93(1), 327-358. doi:10.1152/physrev.00016.2011.

[82] Monroe, D., \& Hoffman, M. (2001). A Cell-based Model of Hemostasis. Thrombosis and Haemostasis, 85(06), 958-965. doi:10.1055/s-0037-1615947.

[83] Vine, A. K. (2009). Recent Advances in Haemostasis and Thrombosis. Retina, $29(1), \quad 1-7$. doi:10.1097/iae.0b013e31819091dc. 
[84] Drake, T. A., Morrissey, J. H., \& Edgington, T. S. (1989). Selective cellular expression of tissue factor in human tissues. Implications for disorders of hemostasis and thrombosis. The American journal of pathology, 134(5), 1087.

[85] Lin, M. C., Almus-Jacobs, F., Chen, H. H., Parry, G. C., Mackman, N., Shyy, J. Y., \& Chien, S. (1997). Shear stress induction of the tissue factor gene. Journal of Clinical Investigation, 99(4), 737-744. doi:10.1172/jci119219.

[86] Yan, S.-F., Lu, J., Zou, Y. S., Kisiel, W., Mackman, N., Leitges, M., ... Stern, D. (2000). Protein Kinase C- $\beta$ and Oxygen Deprivation. Journal of Biological Chemistry, 275(16), 11921-11928. doi:10.1074/jbc.275.16.11921.

[87] Kamimura, M., Bea, F., Akizawa, T., Katus, H. A., Kreuzer, J., \& Viedt, C. (2004). Platelet-Derived Growth Factor Induces Tissue Factor Expression in Vascular Smooth Muscle Cells via Activation of Egr-1. Hypertension, 44(6), 944-951. doi:10.1161/01.hyp.0000146908.75091.99.

[88] Schecter, A. D., Rollins, B. J., Zhang, Y. J., Charo, I. F., Fallon, J. T., Rossikhina, M., ... Taubman, M. B. (1997). Tissue Factor Is Induced by Monocyte Chemoattractant Protein-1 in Human Aortic Smooth Muscle and THP-1 Cells. Journal of Biological Chemistry, 272(45), 28568-28573. doi:10.1074/jbc.272.45.28568.

[89] Giesen, P. L. A., Rauch, U., Bohrmann, B., Kling, D., Roque, M., Fallon, J. T., ... Nemerson, Y. (1999). Blood-borne tissue factor: Another view of thrombosis. Proceedings of the National Academy of Sciences, 96(5), $2311-2315$. doi:10.1073/pnas.96.5.2311.

[90] Kao, K. J., Pizzo, S. V., \& McKee, P. A. (1979). Demonstration and characterization of specific binding sites for factor VIII/von Willebrand factor on human platelets. Journal of Clinical Investigation, 63(4), 656-664. doi:10.1172/jci109348.

[91] Weisel, J. W., Nagaswami, C., Vilaire, G., \& Bennett, J. S. (1992). Examination of the platelet membrane glycoprotein IIb-IIIa complex and its interaction with fibrinogen and other ligands by electron microscopy. Journal of Biological Chemistry, 267(23), 16637-16643.

[92] Goto, S., Ikeda, Y., Saldívar, E., \& Ruggeri, Z. M. (1998). Distinct mechanisms of platelet aggregation as a consequence of different shearing flow conditions. Journal of Clinical Investigation, 101(2), 479-486. doi:10.1172/jci973.

[93] Kalafatis, M., Swords, N. A., Rand, M. D., \& Mann, K. G. (1994). Membrane-dependent reactions in blood coagulation: role of the vitamin K-dependent enzyme complexes. Biochimica et Biophysica Acta (BBA) - Molecular Basis of Disease, 1227(3), 113-129. doi:10.1016/0925-4439(94)90086-8.

[94] Blair, P., \& Flaumenhaft, R. (2009). Platelet $\alpha$-granules: Basic biology and clinical correlates. Blood Reviews, 23(4), $177-189$. doi:10.1016/j.blre.2009.04.001.

[95] Holmsen, H., \& Weiss, H. J. (1979). Secretable Storage Pools in Platelets. Annual Review of Medicine, 30(1), 119-134. doi:10.1146/annurev.me.30.020179.001003.

[96] Antoniades, C., Bakogiannis, C., Tousoulis, D., Demosthenous, M., Marinou, K., \& Stefanadis, C. (2010). Platelet Activation in Atherogenesis Associated with Low-Grade Inflammation. Inflammation \& Allergy - Drug Targets, 9(5), 334-345. doi:10.2174/187152810793938035.

[97] Boilard, E., Nigrovic, P. A., Larabee, K., Watts, G. F. M., Coblyn, J. S., Weinblatt, M. E., ... Lee, D. M. (2010). Platelets Amplify Inflammation in Arthritis via Collagen-Dependent Microparticle Production. Science, 327(5965), $580-583$. doi:10.1126/science.1181928.

[98] Coral-Alvarado, P., Quintana, G., Garces, M. F., Cepeda, L. A., Caminos, J. E., Rondon, F., ... Restrepo, J. F. (2008). Potential biomarkers for detecting pulmonary arterial hypertension in patients with systemic sclerosis. Rheumatology International, 29(9), 1017-1024. doi:10.1007/s00296-008-0829-8.

[99] Cefle, A., Inanc, M., Sayarlioglu, M., Kamali, S., Gul, A., Ocal, L., ... Konice, M. (2009). Pulmonary hypertension in systemic lupus erythematosus: relationship with antiphospholipid antibodies and severe disease outcome. Rheumatology International, 31(2), 183-189. doi:10.1007/s00296-009-1255-2

[100] Palta, S., Saroa, R., \& Palta, A. (2014). Overview of the coagulation system. Indian Journal of Anaesthesia, 58(5), 515. doi:10.4103/0019-5049.144643.

[101] Kumar, N. G., Clark, A., Roztocil, E., Caliste, X., Gillespie, D. L., \& Cullen, J. P. (2015). Fibrinolytic activity of endothelial cells from different venous beds. Journal of Surgical Research, 194(1), 297-303. doi:10.1016/j.jss.2014.09.028.

[102] Palmer, R. M. J., Ferrige, A. G., \& Moncada, S. (1987). Nitric oxide release accounts for the biological activity of endothelium-derived relaxing factor. Nature, 327(6122), 524-526. doi:10.1038/327524a0.

[103] Moncada, S., Gryglewski, R., Bunting, S., \& Vane, J. R. (1976). An enzyme isolated from arteries transforms prostaglandin endoperoxides to an unstable substance that inhibits platelet aggregation. Nature, 263(5579), $663-665$. doi:10.1038/263663a0. 
[104] Botting, R., \& Vane, J. R. (1989). Mediators and the Anti-Thrombotic Properties of the Vascular Endothelium. Annals of Medicine, 21(1), 31-38. doi:10.3109/07853898909149179.

[105] Westein, E., van der Meer, A. D., Kuijpers, M. J. E., Frimat, J.-P., van den Berg, A., \& Heemskerk, J. W. M. (2013). Atherosclerotic geometries exacerbate pathological thrombus formation poststenosis in a von Willebrand factor-dependent manner. Proceedings of the National Academy of Sciences, 110(4), 1357-1362. doi:10.1073/pnas.1209905110.

[106] Jain, A., Barrile, R., van der Meer, A., Mammoto, A., Mammoto, T., De Ceunynck, K., ... Ingber, D. (2017). Primary Human Lung Alveolus-on-a-chip Model of Intravascular Thrombosis for Assessment of Therapeutics. Clinical Pharmacology \& Therapeutics, 103(2), 332-340. doi:10.1002/cpt.742.

[107] Eisenberg, P. R., Lucore, C., Kaufman, L., Sobel, B. E., Jaffe, A. S., \& Rich, S. (1990). Fibrinopeptide A levels indicative of pulmonary vascular thrombosis in patients with primary pulmonary hypertension. Circulation, 82(3), 841-847. doi:10.1161/01.cir.82.3.841.

[108] Kawut, S. M., Horn, E. M., Berekashvili, K. K., Widlitz, A. C., Rosenzweig, E. B., \& Barst, R. J. (2005). von Willebrand Factor Independently Predicts Long-term Survival in Patients With Pulmonary Arterial Hypertension. Chest, 128(4), 23552362. doi:10.1378/chest.128.4.2355.

[109] Tournier, A., Wahl, D., Chaouat, A., Max, J.-P., Regnault, V., Lecompte, T., \& Chabot, F. (2010). Calibrated automated thrombography demonstrates hypercoagulability in patients with idiopathic pulmonary arterial hypertension. Thrombosis Research, 126(6), e418-e422. doi:10.1016/j.thromres.2010.08.020.

[110] White, R. J., Meoli, D. F., Swarthout, R. F., Kallop, D. Y., Galaria, I. I., Harvey, J. L., ... Taubman, M. B. (2007). Plexiformlike lesions and increased tissue factor expression in a rat model of severe pulmonary arterial hypertension. American Journal of Physiology-Lung Cellular and Molecular Physiology, 293(3), L583-L590. doi:10.1152/ajplung.00321.2006.

[111] Lopes, A. A., Barreto, A. C., Maeda, N. Y., Cícero, C., Soares, R. P. S., Bydlowski, S. P., \& Rich, S. (2011). Plasma von Willebrand factor as a predictor of survival in pulmonary arterial hypertension associated with congenital heart disease. Brazilian Journal of Medical and Biological Research, 44(12), 1269-1275. doi:10.1590/s0100-879x2011007500149.

[112] Weerackody, R. P., Welsh, D. J., Wadsworth, R. M., \& Peacock, A. J. (2009). Inhibition of p38 MAPK reverses hypoxiainduced pulmonary artery endothelial dysfunction. American Journal of Physiology-Heart and Circulatory Physiology, 296(5), H1312-H1320. doi:10.1152/ajpheart.00977.2008.

[113] Warner, T. D. (1996). Influence of endothelial mediators on the vascular smooth muscle and circulating platelets and blood cells. International angiology: a journal of the International Union of Angiology, 15(2), 93-99.

[114] Frenette, P. S., Johnson, R. C., Hynes, R. O., \& Wagner, D. D. (1995). Platelets roll on stimulated endothelium in vivo: an interaction mediated by endothelial P-selectin. Proceedings of the National Academy of Sciences, 92(16), 7450-7454. doi:10.1073/pnas.92.16.7450.

[115] McIntyre, T. M., Prescott, S. M., Weyrich, A. S., \& Zimmerman, G. A. (2003). Cell-cell interactions: leukocyte-endothelial interactions. Current Opinion in Hematology, 10(2), 150-158. doi:10.1097/00062752-200303000-00009.

[116] McEver, R. P., Beckstead, J. H., Moore, K. L., Marshall-Carlson, L., \& Bainton, D. F. (1989). GMP-140, a platelet alphagranule membrane protein, is also synthesized by vascular endothelial cells and is localized in Weibel-Palade bodies. Journal of Clinical Investigation, 84(1), 92-99. doi:10.1172/jci114175.

[117] Bernardo, A., Ball, C., Nolasco, L., Moake, J. F., \& Dong, J. (2004). Effects of inflammatory cytokines on the release and cleavage of the endothelial cell-derived ultralarge von Willebrand factor multimers under flow. Blood, 104(1), 100-106. doi:10.1182/blood-2004-01-0107.

[118] Federici, A. B., Bader, R., Pagani, S., Colibretti, M. L., Marco, L., \& Mannucci, P. M. (1989). Binding of von Willebrand factor to glycoproteins Ib and IIb/IIIa complex: affinity is related to multimeric size. British Journal of Haematology, 73(1), 93-99. doi:10.1111/j.1365-2141.1989.tb00226.x.

[119] Savage, B., Saldívar, E., \& Ruggeri, Z. M. (1996). Initiation of Platelet Adhesion by Arrest onto Fibrinogen or Translocation on von Willebrand Factor. Cell, 84(2), 289-297. doi:10.1016/s0092-8674(00)80983-6.

[120] Sporn, L. A., Marder, V. J., \& Wagner, D. D. (1986). Inducible secretion of large, biologically potent von Willebrand factor multimers. Cell, 46(2), 185-190. doi:10.1016/0092-8674(86)90735-x.

[121] Arya, M., Anvari, B., Romo, G. M., Cruz, M. A., Dong, J.-F., McIntire, L. V., ... López, J. (2002). Ultralarge multimers of von Willebrand factor form spontaneous high-strength bonds with the platelet glycoprotein Ib-IX complex: studies using optical tweezers. Blood, 99(11), 3971-3977. doi:10.1182/blood-2001-11-0060.

[122] Doggett, T. A., Girdhar, G., Lawshé, A., Schmidtke, D. W., Laurenzi, I. J., Diamond, S. L., \& Diacovo, T. G. (2002). Selectin-Like Kinetics and Biomechanics Promote Rapid Platelet Adhesion in Flow: The GPIba-vWF Tether Bond. Biophysical Journal, 83(1), 194-205. doi:10.1016/s0006-3495(02)75161-8. 
[123] André, P., Denis, C. V., Ware, J., Saffaripour, S., Hynes, R. O., Ruggeri, Z. M., \& Wagner, D. D. (2000). Platelets adhere to and translocate on von Willebrand factor presented by endothelium in stimulated veins. Blood, 96(10), 3322-3328. doi:10.1182/blood.v96.10.3322.h8003322_3322_3328.

[124] Ruggeri, Z. M., Orje, J. N., Habermann, R., Federici, A. B., \& Reininger, A. J. (2006). Activation-independent platelet adhesion and aggregation under elevated shear stress. Blood, 108(6), 1903-1910. doi:10.1182/blood-2006-04-011551.

[125] Frenette, P. S., Denis, C. V., Weiss, L., Jurk, K., Subbarao, S., Kehrel, B., ... Wagner, D. D. (2000). P-Selectin Glycoprotein Ligand 1 (Psgl-1) Is Expressed on Platelets and Can Mediate Platelet-Endothelial Interactions in Vivo. Journal of Experimental Medicine, 191(8), 1413-1422. doi:10.1084/jem.191.8.1413.

[126] Romo, G. M., Dong, J.-F., Schade, A. J., Gardiner, E. E., Kansas, G. S., Li, C. Q., .. López, J. A. (1999). The Glycoprotein Ib-IX-V Complex Is a Platelet Counterreceptor for P-Selectin. Journal of Experimental Medicine, 190(6), 803-814. doi:10.1084/jem.190.6.803.

[127] Da Costa Martins, P., García-Vallejo, J.-J., van Thienen, J. V., Fernandez-Borja, M., van Gils, J. M., Beckers, C., ... Zwaginga, J.-J. (2007). P-Selectin Glycoprotein Ligand-1 Is Expressed on Endothelial Cells and Mediates Monocyte Adhesion to Activated Endothelium. Arteriosclerosis, Thrombosis, and Vascular Biology, 27(5), $1023-1029$. doi:10.1161/atvbaha.107.140442.

[128] Bombeli, T., Schwartz, B. R., \& Harlan, J. M. (1998). Adhesion of Activated Platelets to Endothelial Cells: Evidence for a GPIIbIIIa-dependent Bridging Mechanism and Novel Roles for Endothelial Intercellular Adhesion Molecule 1 (ICAM-1), avß3 Integrin, and GPIb $\alpha$. Journal of Experimental Medicine, 187(3), 329-339. doi:10.1084/jem.187.3.329.

[129] Naimushin, Y. A., \& Mazurov, A. V. (2004). Von Willebrand factor can support platelet aggregation via interaction with activated GPIIb-IIIa and GPIb. Platelets, 15(7), 419-425. doi:10.1080/09537100410001721333.

[130] Massberg, S., Enders, G., Matos, F. C. de M., Tomic, L. I. D., Leiderer, R., Eisenmenger, S., ... Krombach, F. (1999). Fibrinogen Deposition at the Postischemic Vessel Wall Promotes Platelet Adhesion During Ischemia-Reperfusion In Vivo. Blood, 94(11), 3829-3838. doi:10.1182/blood.v94.11.3829.

[131] Mathur, T., Singh, K. A., R. Pandian, N. K., Tsai, S.-H., Hein, T. W., Gaharwar, A. K., ... Jain, A. (2019). Organ-on-chips made of blood: endothelial progenitor cells from blood reconstitute vascular thromboinflammation in vessel-chips. Lab on a Chip, 19(15), 2500-2511. doi:10.1039/c91c00469f.

[132] Gawaz, M., Neumann, F.-J., Dickfeld, T., Reininger, A., Adelsberger, H., Gebhardt, A., \& Schömig, A. (1997). Vitronectin Receptor ( $\alpha v \beta 3$ ) Mediates Platelet Adhesion to the Luminal Aspect of Endothelial Cells. Circulation, 96(6), 1809-1818. doi:10.1161/01.cir.96.6.1809.

[133] Oguz, M. M., Oguz, A. D., Sanli, C., \& Cevik, A. (2014). Serum Levels of Soluble ICAM-1 in Children with Pulmonary Artery Hypertension. Texas Heart Institute Journal, 41(2), 159-164. doi:10.14503/thij-12-3012.

[134] Arthur Ataam, J., Mercier, O., Lamrani, L., Amsallem, M., Arthur Ataam, J., Arthur Ataam, S., ... Eddahibi, S. (2019). ICAM-1 promotes the abnormal endothelial cell phenotype in chronic thromboembolic pulmonary hypertension. The Journal of Heart and Lung Transplantation, 38(9), 982-996. doi:10.1016/j.healun.2019.06.010.

[135] Burton, V. J., Ciuclan, L. I., Holmes, A. M., Rodman, D. M., Walker, C., \& Budd, D. C. (2011). Bone morphogenetic protein receptor II regulates pulmonary artery endothelial cell barrier function. Blood, 117(1), 333-341. doi:10.1182/blood-2010-05285973.

[136] Nguyen, Q. L., Corey, C., White, P., Watson, A., Gladwin, M. T., Simon, M. A., \& Shiva, S. (2017). Platelets from pulmonary hypertension patients show increased mitochondrial reserve capacity. JCI Insight, 2(5). doi:10.1172/jci.insight.91415.

[137] Suzuki, H., Nakasato, M., Sato, S., Yokoyama, S., Katsuura, M., Yamaki, S., \& Hayasaka, K. (1997). Microangiopathic Hemolytic Anemia and Thrombocytopenia in a Child with Atrial Septal Defect and Pulmonary Hypertension. The Tohoku Journal of Experimental Medicine, 181(3), 379-384. doi:10.1620/tjem.181.379.

[138] Herve, P., Humbert, M., Sitbon, O., Parent, F., Nunes, H., Legal, C., ... Simonneau, G. (2001). Pathobiology of Pulmonary Hypertension. Clinics in Chest Medicine, 22(3), 451-458. doi:10.1016/s0272-5231(05)70283-5.

[139] Haznedaroğlu, I. C., Atalar, E., Oztürk, M. A., Ozer, N., Ovünç, K., Aksöyek, S., ... \& Ozmen, F. (2002). Thrombopoietin inside the pulmonary vessels in patients with and without pulmonary hypertension. Platelets, 13(7), 395-399.

[140] Zheng, Y.-G., Yang, T., Xiong, C.-M., He, J.-G., Liu, Z.-H., Gu, Q., .. Ni, X.-H. (2015). Platelet Distribution Width and Mean Platelet Volume in Idiopathic Pulmonary Arterial Hypertension. Heart, Lung and Circulation, 24(6), 566-572. doi:10.1016/j.hlc.2014.11.025.

[141] Remková, A., Šimková, I., \& Valkovičová, T. (2015). Platelet abnormalities in chronic thromboembolic pulmonary hypertension. International journal of clinical and experimental medicine, 8(6), 9700. 
[142] Yaoita, N., Shirakawa, R., Fukumoto, Y., Sugimura, K., Miyata, S., Miura, Y., ... Horiuchi, H. (2014). Platelets Are Highly Activated in Patients of Chronic Thromboembolic Pulmonary Hypertension. Arteriosclerosis, Thrombosis, and Vascular Biology, 34(11), 2486-2494. doi:10.1161/atvbaha.114.304404.

[143] Suzuki, Y., Yamamoto, M., Wada, H., Ito, M., Nakano, T., Sasaki, Y., ... Nishikawa, M. (1999). Agonist-Induced Regulation of Myosin Phosphatase Activity in Human Platelets Through Activation of Rho-Kinase. Blood, 93(10), $3408-3417$. doi:10.1182/blood.v93.10.3408.410k37_3408_3417.

[144] Nishioka, H., Horiuchi, H., Tabuchi, A., Yoshioka, A., Shirakawa, R., \& Kita, T. (2001). Small GTPase Rho Regulates Thrombin-Induced Platelet Aggregation. Biochemical and Biophysical Research Communications, 280(4), 970-975. doi:10.1006/bbrc.2001.4237.

[145] Can, M. M., Tanboğa, İ. H., Demircan, H. C., Özkan, A., Koca, F., Keleş, N., ... Serebruany, V. (2010). Enhanced hemostatic indices in patients with pulmonary arterial hypertension: An observational study. Thrombosis Research, 126(4), 280-282. doi:10.1016/j.thromres.2010.06.020.

[146] Maeda, N. Y., Bydlowski, S. P., \& Lopes, A. A. (2005). Increased Tyrosine Phosphorylation of Platelet Proteins Including pp125FAK Suggests Endogenous Activation and Aggregation in Pulmonary Hypertension. Clinical and Applied Thrombosis/Hemostasis, 11(4), 411-415. doi:10.1177/107602960501100407.

[147] Rajkumar, R., Konishi, K., Richards, T. J., Ishizawar, D. C., Wiechert, A. C., Kaminski, N., \& Ahmad, F. (2010). Genomewide RNA expression profiling in lung identifies distinct signatures in idiopathic pulmonary arterial hypertension and secondary pulmonary hypertension. American Journal of Physiology-Heart and Circulatory Physiology, 298(4), H1235H1248. doi:10.1152/ajpheart.00254.2009.

[148] Damås, J. K., Otterdal, K., Yndestad, A., Aass, H., Solum, N. O., Frøland, S. S., ... Andreassen, A. K. (2004). Soluble CD40 Ligand in Pulmonary Arterial Hypertension. Circulation, 110(8), 999-1005. doi:10.1161/01.cir.0000139859.68513.fc.

[149] Sase, K., \& Michel, T. (1995). Expression of constitutive endothelial nitric oxide synthase in human blood platelets. Life Sciences, 57(22), 2049-2055. doi:10.1016/0024-3205(95)02191-k.

[150] Gambaryan, S., \& Tsikas, D. (2015). A review and discussion of platelet nitric oxide and nitric oxide synthase: do blood platelets produce nitric oxide from 1-arginine or nitrite? Amino Acids, 47(9), 1779-1793. doi:10.1007/s00726-015-1986-1.

[151] Aytekin, M., Aulak, K. S., Haserodt, S., Chakravarti, R., Cody, J., Minai, O. A., \& Dweik, R. A. (2012). Abnormal platelet aggregation in idiopathic pulmonary arterial hypertension: role of nitric oxide. American Journal of Physiology-Lung Cellular and Molecular Physiology, 302(6), L512-L520. doi:10.1152/ajplung.00289.2011.

[152] Trepakova, E. S., Cohen, R. A., \& Bolotina, V. M. (1999). Nitric Oxide Inhibits Capacitative Cation Influx in Human Platelets by Promoting Sarcoplasmic/Endoplasmic Reticulum Ca2+-ATPase-Dependent Refilling of Ca2+Stores. Circulation Research, 84(2), 201-209. doi:10.1161/01.res.84.2.201.

[153] Iyú, D., Atucha, N. M., Martínez-Prieto, C., Ortiz, M. C., \& García-Estañ, J. (2004). Cell Communication and Signaling, 2(1), 1. doi:10.1186/1478-811x-2-1.

[154] Camilletti, A. (2001). Decreased nitric oxide levels and increased calcium content in platelets of hypertensive patients. American Journal of Hypertension, 14(4), 382-386. doi:10.1016/s0895-7061(00)01297-8.

[155] Nesbitt, W. S., Westein, E., Tovar-Lopez, F. J., Tolouei, E., Mitchell, A., Fu, J., .. Jackson, S. P. (2009). A shear gradientdependent platelet aggregation mechanism drives thrombus formation. Nature Medicine, 15(6), 665-673. doi:10.1038/nm.1955.

[156] Chien, S. (2007). Mechanotransduction and endothelial cell homeostasis: the wisdom of the cell. American Journal of Physiology-Heart and Circulatory Physiology, 292(3), H1209-H1224. doi:10.1152/ajpheart.01047.2006.

[157] Estrada, R., Giridharan, G. A., Nguyen, M.-D., Prabhu, S. D., \& Sethu, P. (2011). Microfluidic endothelial cell culture model to replicate disturbed flow conditions seen in atherosclerosis susceptible regions. Biomicrofluidics, 5(3), 032006. doi:10.1063/1.3608137.

[158] Brooks, A. R., Lelkes, P. I., \& Rubanyi, G. M. (2002). Gene expression profiling of human aortic endothelial cells exposed to disturbed flow and steady laminar flow. Physiological Genomics, 9(1), 27-41. doi:10.1152/physiolgenomics.00075.2001.

[159] Schneider, S. W., Nuschele, S., Wixforth, A., Gorzelanny, C., Alexander-Katz, A., Netz, R. R., \& Schneider, M. F. (2007). Shear-induced unfolding triggers adhesion of von Willebrand factor fibers. Proceedings of the National Academy of Sciences, 104(19), 7899-7903. doi:10.1073/pnas.0608422104.

[160] Kim, J., Zhang, C.-Z., Zhang, X., \& Springer, T. A. (2010). A mechanically stabilized receptor-ligand flex-bond important in the vasculature. Nature, 466(7309), 992-995. doi:10.1038/nature09295. 
[161] Tuder, R. M., Chacon, M., Alger, L., Wang, J., Taraseviciene-Stewart, L., Kasahara, Y., ... Voelkel, N. F. (2001). Expression of angiogenesis-related molecules in plexiform lesions in severe pulmonary hypertension: evidence for a process of disordered angiogenesis. The Journal of Pathology, 195(3), 367-374. doi:10.1002/path.953.

[162] He, H., Venema, V. J., Gu, X., Venema, R. C., Marrero, M. B., \& Caldwell, R. B. (1999). Vascular Endothelial Growth Factor Signals Endothelial Cell Production of Nitric Oxide and Prostacyclin through Flk-1/KDR Activation of c-Src. Journal of Biological Chemistry, 274(35), 25130-25135. doi:10.1074/jbc.274.35.25130.

[163] Partovian, C., Adnot, S., Raffestin, B., Louzier, V., Levame, M., Mavier, I. M., ... Eddahibi, S. (2000). Adenovirus-Mediated Lung Vascular Endothelial Growth Factor Overexpression Protects against Hypoxic Pulmonary Hypertension in Rats. American Journal of Respiratory Cell and Molecular Biology, 23(6), 762-771. doi:10.1165/ajrcmb.23.6.4106.

[164] Campbell, A. I. M., Zhao, Y., Sandhu, R., \& Stewart, D. J. (2001). Cell-Based Gene Transfer of Vascular Endothelial Growth Factor Attenuates Monocrotaline-Induced Pulmonary Hypertension. Circulation, 104(18), $2242-2248$. doi:10.1161/hc4201.097838.

[165] Klein, M., Schermuly, R. T., Ellinghaus, P., Milting, H., Riedl, B., Nikolova, S., ... Schäfer, S. (2008). Combined Tyrosine and Serine/Threonine Kinase Inhibition by Sorafenib Prevents Progression of Experimental Pulmonary Hypertension and Myocardial Remodeling. Circulation, 118(20), 2081-2090. doi:10.1161/circulationaha.108.779751.

[166] Taraseviciene-Stewart, L., Scerbavicius, R., Choe, K.-H., Cool, C., Wood, K., Tuder, R. M., ... Voelkel, N. F. (2006). Simvastatin causes endothelial cell apoptosis and attenuates severe pulmonary hypertension. American Journal of Physiology-Lung Cellular and Molecular Physiology, 291(4), L668-L676. doi:10.1152/ajplung.00491.2005.

[167] Eddahibi, S., Humbert, M., Sediame, S., Chouaid, C., Partovian, C., Maître, B., ... Adnot, S. (2000). Imbalance between Platelet Vascular Endothelial Growth Factor and Platelet-derived Growth Factor in Pulmonary Hypertension. American Journal of Respiratory and Critical Care Medicine, 162(4), 1493-1499. doi:10.1164/ajrccm.162.4.2003124.

[168] Benisty, J. I., McLaughlin, V. V., Landzberg, M. J., Rich, J. D., Newburger, J. W., Rich, S., \& Folkman, J. (2004). Elevated Basic Fibroblast Growth Factor Levels in Patients With Pulmonary Arterial Hypertension. Chest, 126(4), $1255-1261$. doi:10.1378/chest.126.4.1255.

[169] Jurasz, P., Ng, D., Granton, J. T., Courtman, D. W., \& Stewart, D. J. (2010). Elevated platelet angiostatin and circulating endothelial microfragments in idiopathic pulmonary arterial hypertension: A preliminary study. Thrombosis Research, 125(1), 53-60. doi:10.1016/j.thromres.2009.04.005.

[170] Zucker, S., Mirza, H., Conner, C. E., Lorenz, A. F., Drews, M. H., Bahou, W. F., \& Jesty, J. (1998). Vascular endothelial groth factor induces tissue factor and matrix metalloproteinase production in endothelial cells: Conversion of prothrombin to thrombin results in progelatininase a activation and cell proliferation. International journal of cancer, 75(5), 780-786. doi:10.1002/(sici)1097-0215(19980302)75:5<780::aid-ijc19>3.0.co;2-a.

[171] Yu, Y., Sweeney, M., Zhang, S., Platoshyn, O., Landsberg, J., Rothman, A., \& Yuan, J. X.-J. (2003). PDGF stimulates pulmonary vascular smooth muscle cell proliferation by upregulating TRPC6 expression. American Journal of PhysiologyCell Physiology, 284(2), C316-C330. doi:10.1152/ajpcell.00125.2002.

[172] Yamboliev, I. A., \& Gerthoffer, W. T. (2001). Modulatory role of ERK MAPK-caldesmon pathway in PDGF- stimulated migration of cultured pulmonary artery SMCs. American Journal of Physiology-Cell Physiology, 280(6), C1680-C1688. doi:10.1152/ajpcell.2001.280.6.c1680.

[173] Humbert, M., Monti, G., Fartoukh, M., Magnan, A., Brenot, F., Rain, B., ... \& Emilie, D. (1998). Platelet-derived growth factor expression in primary pulmonary hypertension: comparison of HIV seropositive and HIV seronegative patients. European Respiratory Journal, 11(3), 554-559.

[174] Jankov, R. P., Kantores, C., Belcastro, R., Yi, S., Ridsdale, R. A., Post, M., \& Tanswell, A. K. (2005). A role for plateletderived growth factor $\beta$-receptor in a newborn rat model of endothelin-mediated pulmonary vascular remodeling. American Journal of Physiology-Lung Cellular and Molecular Physiology, 288(6), L1162-L1170. doi:10.1152/ajplung.00180.2004.

[175] Schermuly, R. T. (2005). Reversal of experimental pulmonary hypertension by PDGF inhibition. Journal of Clinical Investigation, 115(10), 2811-2821. doi:10.1172/jci24838.

[176] Jurasz, P., Alonso, D., Castro-Blanco, S., Murad, F., \& Radomski, M. W. (2003). Generation and role of angiostatin in human platelets. Blood, 102(9), 3217-3223. doi:10.1182/blood-2003-02-0378.

[177] Chen, Y.-H., Wu, H.-L., Chen, C.-K., Huang, Y.-H., Yang, B.-C., \& Wu, L.-W. (2003). Angiostatin antagonizes the action of VEGF-A in human endothelial cells via two distinct pathways. Biochemical and Biophysical Research Communications, 310(3), 804-810. doi:10.1016/j.bbrc.2003.09.081.

[178] Pascaud, M.-A., Griscelli, F., Raoul, W., Marcos, E., Opolon, P., Raffestin, B., ... Eddahibi, S. (2003). Lung Overexpression of Angiostatin Aggravates Pulmonary Hypertension in Chronically Hypoxic Mice. American Journal of Respiratory Cell and Molecular Biology, 29(4), 449-457. doi:10.1165/rcmb.2002-0120oc. 
[179] Roth, M., Nauck, M., Yousefi, S., Tamm, M., Blaser, K., Perruchoud, A. P., \& Simon, H. U. (1996). Platelet-activating factor exerts mitogenic activity and stimulates expression of interleukin 6 and interleukin 8 in human lung fibroblasts via binding to its functional receptor. Journal of Experimental Medicine, 184(1), 191-201. doi:10.1084/jem.184.1.191.

[180] Nauck, M., Roth, M., Tamm, M., Eickelberg, O., Wieland, H., Stulz, P., \& Perruchoud, A. P. (1997). Induction of vascular endothelial growth factor by platelet-activating factor and platelet-derived growth factor is downregulated by corticosteroids. American Journal of Respiratory Cell and Molecular Biology, 16(4), 398-406. doi:10.1165/ajrcmb.16.4.9115750.

[181] Caplan, M. S., Hsueh, W., Sun, X.-M., Gidding, S. S., \& Hageman, J. R. (1990). Circulating Plasma Platelet Activating Factor in Persistent Pulmonary Hypertension of the Newborn. American Review of Respiratory Disease, 142(6_pt_1), 12581262. doi:10.1164/ajrccm/142.6_pt_1.1258.

[182] Ono, S., Westcott, J. Y., \& Voelkel, N. F. (1992). PAF antagonists inhibit pulmonary vascular remodeling induced by hypobaric hypoxia in rats. Journal of Applied Physiology, 73(3), 1084-1092. doi:10.1152/jappl.1992.73.3.1084.

[183] Bixby, C. E., Ibe, B. O., Abdallah, M. F., Zhou, W., Hislop, A. A., Longo, L. D., \& Raj, J. U. (2007). Role of plateletactivating factor in pulmonary vascular remodeling associated with chronic high altitude hypoxia in ovine fetal lambs. American Journal of Physiology-Lung Cellular and Molecular Physiology, 293(6), L1475-L1482. doi:10.1152/ajplung.00089.2007.

[184] Beikmann, B. S., Tomlinson, I. D., Rosenthal, S. J., \& Andrews, A. M. (2012). Serotonin Uptake Is Largely Mediated by Platelets versus Lymphocytes in Peripheral Blood Cells. ACS Chemical Neuroscience, 4(1), 161-170. doi:10.1021/cn300146w.

[185] Morecroft, I., Loughlin, L., Nilsen, M., Colston, J., Dempsie, Y., Sheward, J., .. MacLean, M. R. (2005). Functional Interactions between 5-Hydroxytryptamine Receptors and the Serotonin Transporter in Pulmonary Arteries. Journal of Pharmacology and Experimental Therapeutics, 313(2), 539-548. doi:10.1124/jpet.104.081182.

[186] Lannan, K. L., Phipps, R. P., \& White, R. J. (2014). Thrombosis, platelets, microparticles and PAH: more than a clot. Drug Discovery Today, 19(8), 1230-1235. doi:10.1016/j.drudis.2014.04.001.

[187] Hervé, P., Launay, J.-M., Scrobohaci, M.-L., Brenot, F., Simonneau, G., Petitpretz, P., ... Drouet, L. (1995). Increased plasma serotonin in primary pulmonary hypertension. The American Journal of Medicine, 99(3), $249-254$. doi:10.1016/s0002-9343(99)80156-9.

[188] Kéreveur, A., Callebert, J., Humbert, M., Hervé, P., Simonneau, G., Launay, J.-M., \& Drouet, L. (2000). High Plasma Serotonin Levels in Primary Pulmonary Hypertension. Arteriosclerosis, Thrombosis, and Vascular Biology, 20(10), 22332239. doi:10.1161/01.atv.20.10.2233.

[189] Lederer, D. J., Horn, E. M., Rosenzweig, E. B., Karmally, W., Jahnes, M., Barst, R. J., \& Kawut, S. M. (2008). Plasma serotonin levels are normal in pulmonary arterial hypertension. Pulmonary Pharmacology \& Therapeutics, 21(1), 112-114. doi:10.1016/j.pupt.2007.01.003.

[190] Breuer, J., Georgaraki, A., Sieverding, L., Baden, W., \& Apitz, J. (1996). Increased turnover of serotonin in children with pulmonary hypertension secondary to congenital heart disease. Pediatric Cardiology, 17(4), 214-219. doi:10.1007/bf02524796.

[191] Launay, J.-M., Hervé, P., Peoc'h, K., Tournois, C., Callebert, J., Nebigil, C. G., .. Maroteaux, L. (2002). Function of the serotonin 5-hydroxytryptamine 2B receptor in pulmonary hypertension. Nature Medicine, 8(10), 1129-1135. doi:10.1038/nm764.

[192] Marcos, E., Fadel, E., Sanchez, O., Humbert, M., Dartevelle, P., Simonneau, G., ... Eddahibi, S. (2005). Serotonin Transporter and Receptors in Various Forms of Human Pulmonary Hypertension. Chest, 128(6), 552S-553S. doi:10.1378/chest.128.6_suppl.552s.

[193] Abenhaim, L. (1996). Appetite-Suppressant Drugs and Risk of Primary Pulmonary Hypertension. The Nurse Practitioner, 21(11), 118. doi:10.1097/00006205-199611000-00011.

[194] Eddahibi, S., \& Adnot, S. (2002). Anorexigen-induced pulmonary hypertension and the serotonin (5-HT) hypothesis: lessons for the future in pathogenesis. Respiratory Research, 3(1), 9. doi:10.1186/rr181.

[195] Guilluy, C., Eddahibi, S., Agard, C., Guignabert, C., Izikki, M., Tu, L., ... Pacaud, P. (2009). RhoA and Rho Kinase Activation in Human Pulmonary Hypertension. American Journal of Respiratory and Critical Care Medicine, 179(12), 11511158. doi:10.1164/rccm.200805-691oc.

[196] Cogolludo, A., Moreno, L., Lodi, F., Frazziano, G., Cobeño, L., Tamargo, J., \& Perez-Vizcaino, F. (2006). Serotonin Inhibits Voltage-Gated K + Currents in Pulmonary Artery Smooth Muscle Cells. Circulation Research, 98(7), 931-938. doi:10.1161/01.res.0000216858.04599.e1. 
[197] Welsh, D. J., Harnett, M., MacLean, M., \& Peacock, A. J. (2004). Proliferation and Signaling in Fibroblasts. American Journal of Respiratory and Critical Care Medicine, 170(3), 252-259. doi:10.1164/rccm.200302-264oc.

[198] White, R. J. (2012). Thrombin and Platelets in Pulmonary Hypertension: A Lot More Than Clot. Advances in Pulmonary Hypertension, 11(1), 19-24. doi:10.21693/1933-088x-11.1.19.

[199] Cloutier, N., Paré, A., Farndale, R. W., Schumacher, H. R., Nigrovic, P. A., Lacroix, S., \& Boilard, E. (2012). Platelets can enhance vascular permeability. Blood, 120(6), 1334-1343. doi:10.1182/blood-2012-02-413047.

[200] J. E. Leysen, D. de Chaffoy de Courcelles, F. De Clerck, C. J. E. Niemegeers, and J. M. Van nueten, (1984). Serotonin-S2 receptor binding sites and functional correlates. Neuropharmacology, 23(12), 1493-1501. doi:10.1016/0028-3908(84)900935.

[201] Li, J.-J., Huang, Y.-Q., Basch, R., \& Karpatkin, S. (2001). Thrombin Induces the Release of Angiopoietin-1 from Platelets. Thrombosis and Haemostasis, 85(02), 204-206. doi:10.1055/s-0037-1615677.

[202] Sullivan, C. C., Du, L., Chu, D., Cho, A. J., Kido, M., Wolf, P. L., ... Thistlethwaite, P. A. (2003). Induction of pulmonary hypertension by an angiopoietin 1/TIE2/serotonin pathway. Proceedings of the National Academy of Sciences, 100(21), 12331-12336. doi:10.1073/pnas.1933740100.

[203] Quarck, R., Nawrot, T., Meyns, B., \& Delcroix, M. (2009). C-Reactive Protein. Journal of the American College of Cardiology, 53(14), 1211-1218. doi:10.1016/j.jacc.2008.12.038.

[204] Langer, F., Schramm, R., Bauer, M., Tscholl, D., Kunihara, T., \& Scha“fers, H.-J. (2004). Cytokine Response to Pulmonary Thromboendarterectomy. Chest, 126(1), 135-141. doi:10.1378/chest.126.1.135.

[205] Pietravalle, F., Lecoanet-Henchoz, S., Blasey, H., Aubry, J.-P., Elson, G., Edgerton, M. D., ... Gauchat, J.-F. (1996). Human Native Soluble CD40L Is a Biologically Active Trimer, Processed Inside Microsomes. Journal of Biological Chemistry, 271(11), 5965-5967. doi:10.1074/jbc.271.11.5965.

[206] Kotowicz, K. et al., (2000). Biological function of CD40 on human endothelial cells: costimulation with CD40 ligand and interleukin-4 selectively induces expression of vascular cell adhesion molecule-1 and P-selectin resulting in preferential adhesion of lymphocytes. Immunology, 100(4), pp.441-448. Available at: http://dx.doi.org/10.1046/j.13652567.2000.00061.x..

[207] Zhang, Y., Cao, H. J., Graf, B., Meekins, H., Smith, T. J., \& Phipps, R. P. (1998). Cutting edge: CD40 engagement upregulates cyclooxygenase-2 expression and prostaglandin E2 production in human lung fibroblasts. The Journal of Immunology, 160(3), 1053-1057.

[208] Mach, F., Schönbeck, U., Sukhova, G. K., Atkinson, E., \& Libby, P. (1998). Reduction of atherosclerosis in mice by inhibition of CD40 signalling. Nature, 394(6689), 200-203. doi:10.1038/28204.

[209] Chatterjee, M., von Ungern-Sternberg, S. N. I., Seizer, P., Schlegel, F., Büttcher, M., Sindhu, N. A., ... Gawaz, M. (2015). Platelet-derived CXCL12 regulates monocyte function, survival, differentiation into macrophages and foam cells through differential involvement of CXCR4-CXCR7. Cell Death \& Disease, 6(11), e1989-e1989. doi:10.1038/cddis.2015.233.

[210] Yu, L., \& Hales, C. A. (2011). Effect of chemokine receptor CXCR4 on hypoxia-induced pulmonary hypertension and vascular remodeling in rats. Respiratory Research, 12(1). doi:10.1186/1465-9921-12-21.

[211] Sartina, E., Suguihara, C., Ramchandran, S., Nwajei, P., Rodriguez, M., Torres, E., ... Young, K. C. (2012). Antagonism of CXCR7 attenuates chronic hypoxia-induced pulmonary hypertension. Pediatric Research, 71(6), 682-688. doi:10.1038/pr.2012.30.

[212] Costello, C. M., McCullagh, B., Howell, K., Sands, M., Belperio, J. A., Keane, M. P., .. McLoughlin, P. (2011). A role for the CXCL12 receptor, CXCR7, in the pathogenesis of human pulmonary vascular disease. European Respiratory Journal, 39(6), 1415-1424. doi:10.1183/09031936.00044911.

[213] McCullagh, B. N., Costello, C. M., Li, L., O’Connell, C., Codd, M., Lawrie, A., ... Gaine, S. (2015). Elevated Plasma CXCL1 $2 \alpha$ Is Associated with a Poorer Prognosis in Pulmonary Arterial Hypertension. PLOS ONE, 10(4), e0123709. doi:10.1371/journal.pone.0123709.

[214] Mauri, D. N., Ebner, R., Montgomery, R. I., Kochel, K. D., Cheung, T. C., Yu, G.-L., ... Ware, C. F. (1998). LIGHT, a New Member of the TNF Superfamily, and Lymphotoxin $\alpha$ Are Ligands for Herpesvirus Entry Mediator. Immunity, 8(1), 21-30. doi:10.1016/s1074-7613(00)80455-0.

[215] Otterdal, K., Smith, C., Øie, E., Pedersen, T. M., Yndestad, A., Stang, E., ... Damås, J. K. (2006). Platelet-derived LIGHT induces inflammatory responses in endothelial cells and monocytes. Blood, 108(3), 928-935. doi:10.1182/blood-2005-09010629 . 
[216] Otterdal, K., Andreassen, A. K., Yndestad, A., Øie, E., Sandberg, W. J., Dahl, C. P., ... Damås, J. K. (2008). Raised LIGHT Levels in Pulmonary Arterial Hypertension. American Journal of Respiratory and Critical Care Medicine, 177(2), $202-207$. doi:10.1164/rccm.200703-506oc.

[217] Franscini, N., Bachli, E. B., Blau, N., Fischler, M., Walter, R. B., Schaffner, A., \& Schoedon, G. (2004). Functional Tetrahydrobiopterin Synthesis in Human Platelets. Circulation, 110(2), 186-192. doi:10.1161/01.cir.0000134281.82972.57.

[218] Khoo, J. P., Zhao, L., Alp, N. J., Bendall, J. K., Nicoli, T., Rockett, K., ... Channon, K. M. (2005). Pivotal Role for Endothelial Tetrahydrobiopterin in Pulmonary Hypertension. Circulation, 111(16), 2126-2133. doi:10.1161/01.cir.0000162470.26840.89.

[219] Diamant, M., Tushuizen, M. E., Sturk, A., \& Nieuwland, R. (2004). Cellular microparticles: new players in the field of vascular disease? European Journal of Clinical Investigation, 34(6), 392-401. doi:10.1111/j.1365-2362.2004.01355.x.

[220] Diehl, P., Aleker, M., Helbing, T., Sossong, V., Germann, M., Sorichter, S., ... Moser, M. (2010). Increased platelet, leukocyte and endothelial microparticles predict enhanced coagulation and vascular inflammation in pulmonary hypertension. Journal of Thrombosis and Thrombolysis, 31(2), 173-179. doi:10.1007/s11239-010-0507-z.

[221] Kireev, D., Popenko, N., Pichugin, A., Panteleev, M., Krymskaya, O., Ataullakhanov, F., \& Sinauridze, E. (2007). Platelet microparticle membranes have 50- to 100 -fold higher specific procoagulant activity than activated platelets. Thrombosis and Haemostasis, 97(03), 425-434. doi:10.1160/th06-06-0313.

[222] Bakouboula, B., Morel, O., Faure, A., Zobairi, F., Jesel, L., Trinh, A., ... Toti, F. (2008). Procoagulant Membrane Microparticles Correlate with the Severity of Pulmonary Arterial Hypertension. American Journal of Respiratory and Critical Care Medicine, 177(5), 536-543. doi:10.1164/rccm.200706-840oc.

[223] Pfister, S. L. (2004). Role of Platelet Microparticles in the Production of Thromboxane by Rabbit Pulmonary Artery. Hypertension, 43(2), 428-433. doi:10.1161/01.hyp.0000110906.77479.91.

[224] Pakala, R. (2004). Serotonin and thromboxane A2 stimulate platelet-derived microparticle-induced smooth muscle cell proliferation. Cardiovascular Radiation Medicine, 5(1), 20-26. doi:10.1016/j.carrad.2003.12.002.

[225] Brill, A., Dashevsky, O., Rivo, J., Gozal, Y., \& Varon, D. (2005). Platelet-derived microparticles induce angiogenesis and stimulate post-ischemic revascularization. Cardiovascular Research, 67(1), 30-38. doi:10.1016/j.cardiores.2005.04.007.

[226] Tual-Chalot, S., Guibert, C., Muller, B., Savineau, J.-P., Andriantsitohaina, R., \& Martinez, M. C. (2010). Circulating Microparticles from Pulmonary Hypertensive Rats Induce Endothelial Dysfunction. American Journal of Respiratory and Critical Care Medicine, 182(2), 261-268. doi:10.1164/rccm.200909-1347oc.

[227] Visovatti, S. H., Hyman, M. C., Bouis, D., Neubig, R., McLaughlin, V. V., \& Pinsky, D. J. (2012). Increased CD39 Nucleotidase Activity on Microparticles from Patients with Idiopathic Pulmonary Arterial Hypertension. PLoS ONE, 7(7), e40829. doi:10.1371/journal.pone.0040829.

[228] Nomura, S. (2001). High-shear-stress-induced activation of platelets and microparticles enhances expression of cell adhesion molecules in THP-1 and endothelial cells. Atherosclerosis, 158(2), 277-287. doi:10.1016/s0021-9150(01)00433-6.

[229] Sossong, V., Helbing, T., Beyersdorf, F., Olschewski, M., Bode, C., Diehl, P., .. Moser, M. (2008). Increased levels of circulating microparticles in patients with severe aortic valve stenosis. Thrombosis and Haemostasis, 99(04), 711-719. doi:10.1160/th07-05-0334.

[230] Hoeper, M. M., Kramer, T., Pan, Z., Eichstaedt, C. A., Spiesshoefer, J., Benjamin, N., ... Grünig, E. (2017). Mortality in pulmonary arterial hypertension: prediction by the 2015 European pulmonary hypertension guidelines risk stratification model. European Respiratory Journal, 50(2), 1700740. doi:10.1183/13993003.00740-2017.

[231] Kawut, S. M., Horn, E. M., Berekashvili, K. K., Garofano, R. P., Goldsmith, R. L., Widlitz, A. C., .. Barst, R. J. (2005). New predictors of outcome in idiopathic pulmonary arterial hypertension. The American Journal of Cardiology, 95(2), 199203. doi:10.1016/j.amjcard.2004.09.006.

[232] Rich, S., Kaufmann, E., \& Levy, P. S. (1992). The Effect of High Doses of Calcium-Channel Blockers on Survival in Primary Pulmonary Hypertension. New England Journal of Medicine, 327(2), 76-81. doi:10.1056/nejm199207093270203.

[233] Preston, I. R., Roberts, K. E., Miller, D. P., Sen, G. P., Selej, M., Benton, W. W., .. Farber, H. W. (2015). Effect of Warfarin Treatment on Survival of Patients With Pulmonary Arterial Hypertension (PAH) in the Registry to Evaluate Early and LongTerm PAH Disease Management (REVEAL). Circulation, 132(25), 2403-2411. doi:10.1161/circulationaha.115.018435.

[234] Khan, M. S., Usman, M. S., Siddiqi, T. J., Khan, S. U., Murad, M. H., Mookadam, F., ... Rich, J. D. (2018). Is Anticoagulation Beneficial in Pulmonary Arterial Hypertension? Circulation: Cardiovascular Quality and Outcomes, 11(9). doi:10.1161/circoutcomes.118.004757. 
[235] Robbins, I. M. (2006). A study of aspirin and clopidogrel in idiopathic pulmonary arterial hypertension. European Respiratory Journal, 27(3), 578-584. doi:10.1183/09031936.06.00095705.

[236] Kawut, S. M., Bagiella, E., Lederer, D. J., Shimbo, D., Horn, E. M., Roberts, K. E., ... Girgis, R. E. (2011). Randomized Clinical Trial of Aspirin and Simvastatin for Pulmonary Arterial Hypertension. Circulation, 123(25), $2985-2993$. doi:10.1161/circulationaha.110.015693.

[237] Shen, L., Shen, J., Pu, J., \& He, B. (2011). Aspirin Attenuates Pulmonary Arterial Hypertension in Rats by Reducing Plasma 5-Hydroxytryptamine Levels. Cell Biochemistry and Biophysics, 61(1), 23-31. doi:10.1007/s12013-011-9156-x.

[238] Diener, J. L., Daniel Lagassé, H. A., Duerschmied, D., Merhi, Y., Tanguay, J.-F., Hutabarat, R., ... Schaub, R. (2009). Inhibition of von Willebrand factor-mediated platelet activation and thrombosis by the anti-von Willebrand factor A1-domain aptamer ARC1779. Journal of Thrombosis and Haemostasis, 7(7), 1155-1162. doi:10.1111/j.1538-7836.2009.03459.x.

[239] Suzuki, K., Sakai, Y., Hisamichi, N., Taniuchi, Y., Sato, K., Terazaki, C., ... Masuho, Y. (1997). Comparison of the antiplatelet effect of YM337 and abciximab in rhesus monkeys. European Journal of Pharmacology, 336(2-3), 169-176. doi:10.1016/s0014-2999(97)01241-7.

[240] Beghetti, M., Reber, G., de Moerloose, P., Vadas, L., Chiappe, A., Spahr-Schopfer, I., \& Rimensberger, P. C. (2002). Aerosolized iloprost induces a mild but sustained inhibition of platelet aggregation. European Respiratory Journal, 19(3), 518-524. doi:10.1183/09031936.02.00094302.

[241] Sakamaki, F., Kyotani, S., Nagaya, N., Sato, N., Oya, H., Satoh, T., \& Nakanishi, N. (2000). Increased Plasma P-Selectin and Decreased Thrombomodulin in Pulmonary Arterial Hypertension Were Improved by Continuous Prostacyclin Therapy. Circulation, 102(22), 2720-2725. doi:10.1161/01.cir.102.22.2720.

[242] Friedman, R., Mears, J. G., \& Barst, R. J. (1997). Continuous Infusion of Prostacyclin Normalizes Plasma Markers of Endothelial Cell Injury and Platelet Aggregation in Primary Pulmonary Hypertension. Circulation, 96(9), $2782-2784$. doi:10.1161/01.cir.96.9.2782.

[243] Tamburrelli, C., Crescente, M., Izzi, B., Barisciano, M., Donati, M. B., de Gaetano, G., \& Cerletti, C. (2011). Epoprostenol inhibits human platelet-leukocyte mixed conjugate and platelet microparticle formation in whole blood. Thrombosis Research, 128(5), 446-451. doi:10.1016/j.thromres.2011.05.010.

[244] Rabe, K. F., Tenor, H., Dent, G., Schudt, C., Nakashima, M., \& Magnussen, H. (1994). Identification of PDE isozymes in human pulmonary artery and effect of selective PDE inhibitors. American Journal of Physiology-Lung Cellular and Molecular Physiology, 266(5), L536-L543. doi:10.1152/ajplung.1994.266.5.1536.

[245] Ghofrani, H., Voswinckel, R., Reichenberger, F., Olschewski, H., Haredza, P., Karadas, B., ... Grimminger, F. (2004). Differences in hemodynamic and oxygenation responses to three different phosphodiesterase-5 inhibitors in patients with pulmonary arterial hypertensionA randomized prospective study. Journal of the American College of Cardiology, 44(7), 1488-1496. doi:10.1016/s0735-1097(04)01362-2.

[246] Villagra, J., Shiva, S., Hunter, L. A., Machado, R. F., Gladwin, M. T., \& Kato, G. J. (2007). Platelet activation in patients with sickle disease, hemolysis-associated pulmonary hypertension, and nitric oxide scavenging by cell-free hemoglobin. Blood, 110(6), 2166-2172. doi:10.1182/blood-2006-12-061697.

[247] Toque, H. A., Teixeira, C. E., Priviero, F. B. M., Morganti, R. P., Antunes, E., \& De Nucci, G. (2008). Vardenafil, but not sildenafil or tadalafil, has calcium-channel blocking activity in rabbit isolated pulmonary artery and human washed platelets. British Journal of Pharmacology, 154(4), 787-796. doi:10.1038/bjp.2008.141.

[248] McNamara, P. J., Laique, F., Muang-In, S., \& Whyte, H. E. (2006). Milrinone improves oxygenation in neonates with severe persistent pulmonary hypertension of the newborn. Journal of Critical Care, 21(2), 217-222. doi:10.1016/j.jcrc.2006.01.001.

[249] A. Haraldsson s, N. Kieler-Jensen, and S. E. Ricksten, (2001). The Additive Pulmonary Vasodilatory Effects of Inhaled Prostacyclin and Inhaled Milrinone in Postcardiac Surgical Patients with Pulmonary Hypertension. Anesthesia \& Analgesia, 93(6), 1439-1445. doi:10.1097/00000539-200112000-00018.

[250] Wesley, M. C., McGowan, F. X., Castro, R. A., Dissanayake, S., Zurakowski, D., \& DiNardo, J. A. (2009). The Effect of Milrinone on Platelet Activation as Determined by TEG® Platelet MappingTM. Anesthesia \& Analgesia, 108(5), $1425-1429$. doi:10.1213/ane.0b013e3181981fbe.

[251] Samiee-Zafarghandy, S., Raman, S. R., van den Anker, J. N., McHutchison, K., Hornik, C. P., Clark, R. H., \& Brian Smith, P. (2015). Safety of milrinone use in neonatal intensive care units. Early Human Development, 91(1), 31-35. doi:10.1016/j.earlhumdev.2014.10.007.

[252] Patterson, K. C., Weissmann, A., Ahmadi, T., \& Farber, H. W. (2006). Imatinib Mesylate in the Treatment of Refractory Idiopathic Pulmonary Arterial Hypertension. Annals of Internal Medicine, 145(2), 152. doi:10.7326/0003-4819-145-2200607180-00020. 
[253] Keegan, A., Morecroft, I., Smillie, D., Hicks, M. N., \& MacLean, M. R. (2001). Contribution of the 5-HT 1B Receptor to Hypoxia-Induced Pulmonary Hypertension. Circulation Research, 89(12), 1231-1239. doi:10.1161/hh2401.100426.

[254] Shah, S. J., Gomberg-Maitland, M., Thenappan, T., \& Rich, S. (2009). Selective Serotonin Reuptake Inhibitors and the Incidence and Outcome of Pulmonary Hypertension. Chest, 136(3), 694-700. doi:10.1378/chest.08-2823.

[255] Dumitrascu, R., Kulcke, C., Königshoff, M., Kouri, F., Yang, X., Morrell, N., ... \& Grimminger, F. (2011). Terguride ameliorates monocrotaline-induced pulmonary hypertension in rats. European Respiratory Journal, 37(5), 1104-1118.

[256] Ghofrani, H. A., Al-Hiti, H., Vonk-Noordegraaf, A., Behr, J., Neurohr, C., Jansa, P., ... Rosenkranz, S. (2012). Proof-OfConcept Study To Investigate The Efficacy, Hemodynamics And Tolerability Of Terguride Vs. Placebo In Subjects With Pulmonary Arterial Hypertension: Results Of A Double Blind, Randomised, Prospective Phase IIa Study. B19. Update in Clinical Trials of Pulmonary Arterial Hypertension. doi:10.1164/ajrccm-conference.2012.185.1_meetingabstracts.a2496.

[257] Beghetti, M., Sparling, C., Cox, P. N., Stephens, D., \& Adatia, I. (2003). Inhaled NO inhibits platelet aggregation and elevates plasma but not intraplatelet cGMP in healthy human volunteers. American Journal of Physiology-Heart and Circulatory Physiology, 285(2), H637-H642. doi:10.1152/ajpheart.00622.2002.

[258] Matamis, D., Pampori, S., Papathanasiou, A., Papakonstantinou, P., Tsagourias, M., Galiatsou, E., ... Nakos, G. (2012). Inhaled NO and Sildenafil Combination in Cardiac Surgery Patients With Out-of-Proportion Pulmonary Hypertension. Circulation: Heart Failure, 5(1), 47-53. doi:10.1161/circheartfailure.111.963314.

[259] Nelin, L. D., \& Potenziano, J. L. (2019). Inhaled nitric oxide for neonates with persistent pulmonary hypertension of the newborn in the CINRGI study: time to treatment response. BMC Pediatrics, 19(1). doi:10.1186/s12887-018-1368-4.

[260] Hirenallur-S, D. K., Detweiler, N. D., Haworth, S. T., Leming, J. T., Gordon, J. B., \& Rusch, N. J. (2012). Furegrelate, a Thromboxane Synthase Inhibitor, Blunts the Development of Pulmonary Arterial Hypertension in Neonatal Piglets. Pulmonary Circulation, 2(2), 193-200. doi:10.4103/2045-8932.97605.

[261] Mulvaney, E., Reid, H., Bialesova, L., Bouchard, A., Salvail, D., \& Kinsella, B. T. (2020). NTP42, a novel antagonist of the thromboxane receptor, attenuates experimentally induced pulmonary arterial hypertension. doi:10.21203/rs.2.18445/v4.

[262] Kazimierczyk, R., Błaszczak, P., Kowal, K., Jasiewicz, M., Knapp, M., Szpakowicz, A., ... Kamiński, K. A. (2018). The significance of diminished sTWEAK and P-selectin content in platelets of patients with pulmonary arterial hypertension. Cytokine, 107, 52-58. doi:10.1016/j.cyto.2017.11.014.

[263] Falati, S., Gross, P., Merrill-Skoloff, G., Furie, B. C., \& Furie, B. (2002). Real-time in vivo imaging of platelets, tissue factor and fibrin during arterial thrombus formation in the mouse. Nature Medicine, 8(10), 1175-1180. doi:10.1038/nm782.

[264] Oude Egbrink, M. G. A., Tangelder, G. J., Slaaf, D. W., \& Reneman, R. S. (1988). Thromboembolic Reaction Following Wall Puncture in Arterioles and Venules of the Rabbit Mesentery. Thrombosis and Haemostasis, 59(01), 023-028. doi:10.1055/s-0038-1642559.

[265] Carmeliet, P., Moons, L., Stassen, J. M., De Mol, M., Bouché, A., Van den Oord, J. J., ... \& Collen, D. (1997). Vascular wound healing and neointima formation induced by perivascular electric injury in mice. The American journal of pathology, $150(2), 761$

[266] Kuijpers, M. J. E., Munnix, I. C. A., Cosemans, J. M. E. M., Vlijmen, B. J. V., Reutelingsperger, C. P. M., Egbrink, M. G. A. O., \& Heemskerk, J. W. M. (2008). Key Role of Platelet Procoagulant Activity in Tissue Factor-and Collagen-Dependent Thrombus Formation in Arterioles and VenulesIn VivoDifferential Sensitivity to Thrombin Inhibition. Microcirculation, 15(4), 269-282. doi:10.1080/10739680701653517.

[267] Rosen, E. D., Raymond, S., Zollman, A., Noria, F., Sandoval-Cooper, M., Shulman, A., ... Castellino, F. J. (2001). LaserInduced Noninvasive Vascular Injury Models in Mice Generate Platelet- and Coagulation-Dependent Thrombi. The American Journal of Pathology, 158(5), 1613-1622. doi:10.1016/s0002-9440(10)64117-x.

[268] Cerwinka, W. H., Cooper, D., Krieglstein, C. F., Feelisch, M., \& Granger, D. N. (2002). Nitric oxide modulates endotoxininduced platelet-endothelial cell adhesion in intestinal venules. American Journal of Physiology-Heart and Circulatory Physiology, 282(3), H1111-H1117. doi:10.1152/ajpheart.00391.2001.

[269] Mackman, N. (2004). Mouse models in haemostasis and thrombosis. Thrombosis and Haemostasis, 92(09), 440-443. doi:10.1160/th04-07-0414.

[270] Toshner, M., \& Pepke-Zaba, J. (2014). Chronic thromboembolic pulmonary hypertension: time for research in pathophysiology to catch up with developments in treatment. F1000Prime Reports, 6. doi:10.12703/p6-38.

[271] Kim, H., Yung, G. L., Marsh, J. J., Konopka, R. G., Pedersen, C. A., Chiles, P. G., ... Channick, R. N. (2000). Endothelin mediates pulmonary vascular remodelling in a canine model of chronic embolic pulmonary hypertension. European Respiratory Journal, 15(4), 640-648. doi:10.1034/j.1399-3003.2000.15d04.x. 
[272] Moser, K. M., Cantor, J. P., Olman, M., Villespin, I., Graif, J. L., Konopka, R., ... Pedersen, C. (1991). Chronic pulmonary thromboembolism in dogs treated with tranexamic acid. Circulation, 83(4), 1371-1379. doi:10.1161/01.cir.83.4.1371.

[273] Mercier, O., Tivane, A., Raoux, F., Decante, B., Eddahibi, S., Dartevelle, P. G., \& Fadel, E. (2011). A Reliable Piglet Model of Chronic Thrombo-Embolic Pulmonary Hypertension. A106. Chronic Thromboembolic Pulmonary Hypertension: Bench to Bedside. doi:10.1164/ajrccm-conference.2011.183.1_meetingabstracts.a2415.

[274] Kay, J. M., Harris, P., \& Heath, D. (1967). Pulmonary hypertension produced in rats by ingestion of Crotalaria spectabilis seeds. Thorax, 22(2), 176-179. doi:10.1136/thx.22.2.176.

[275] Hislop, A., \& Reid, L. (1976). New findings in pulmonary arteries of rats with hypoxia-induced pulmonary hypertension. British journal of experimental pathology, 57(5), 542-554.

[276] Ciuclan, L., Bonneau, O., Hussey, M., Duggan, N., Holmes, A. M., Good, R., ... Thomas, M. (2011). A Novel Murine Model of Severe Pulmonary Arterial Hypertension. American Journal of Respiratory and Critical Care Medicine, 184(10), 11711182. doi:10.1164/rccm.201103-0412oc.

[277] Baumgartner, H. R. (1973). The role of blood flow in platelet adhesion, fibrin deposition, and formation of mural thrombi. Microvascular Research, 5(2), 167-179. doi:10.1016/0026-2862(73)90069-1.

[278] Jain, A., van der Meer, A. D., Papa, A.-L., Barrile, R., Lai, A., Schlechter, B. L., ... Ingber, D. E. (2016). Assessment of whole blood thrombosis in a microfluidic device lined by fixed human endothelium. Biomedical Microdevices, 18(4). doi:10.1007/s10544-016-0095-6.

[279] Li, M., Hotaling, N. A., Ku, D. N., \& Forest, C. R. (2014). Microfluidic Thrombosis under Multiple Shear Rates and Antiplatelet Therapy Doses. PLoS ONE, 9(1), e82493. doi:10.1371/journal.pone.0082493.

[280] Neeves, K. B., Maloney, S. F., Fong, K. P., Schmaier, A. A., Kahn, M. L., Brass, L. F., \& Diamond, S. L. (2008). Microfluidic focal thrombosis model for measuring murine platelet deposition and stability: PAR4 signaling enhances shearresistance of platelet aggregates. Journal of Thrombosis and Haemostasis, 6(12), 2193-2201. doi:10.1111/j.15387836.2008.03188.x.

[281] Tsai, M., Kita, A., Leach, J., Rounsevell, R., Huang, J. N., Moake, J., ... Lam, W. A. (2012). In vitro modeling of the microvascular occlusion and thrombosis that occur in hematologic diseases using microfluidic technology. Journal of Clinical Investigation, 122(1), 408-418. doi:10.1172/jci58753.

[282] Costa, P. F., Albers, H. J., Linssen, J. E. A., Middelkamp, H. H. T., van der Hout, L., Passier, R., ... van der Meer, A. D. (2017). Mimicking arterial thrombosis in a 3D-printed microfluidic in vitro vascular model based on computed tomography angiography data. Lab on a Chip, 17(16), 2785-2792. doi:10.1039/c7lc00202e.

[283] Bhatia, S. N., \& Ingber, D. E. (2014). Microfluidic organs-on-chips. Nature Biotechnology, 32(8), 760-772. doi:10.1038/nbt.2989.

[284] Van Engeland, N. C. A., Pollet, A. M. A. O., den Toonder, J. M. J., Bouten, C. V. C., Stassen, O. M. J. A., \& Sahlgren, C. M. (2018). A biomimetic microfluidic model to study signalling between endothelial and vascular smooth muscle cells under hemodynamic conditions. Lab on a Chip, 18(11), 1607-1620. doi:10.1039/c8lc00286j.

[285] Jin, Q., Bhatta, A., Pagaduan, J. V., Chen, X., West-Foyle, H., Liu, J., .. Romer, L. H. (2020). Biomimetic human small muscular pulmonary arteries. Science Advances, 6(13), eaaz2598. doi:10.1126/sciadv.aaz2598.

[286] Al-Hilal, T. A., Keshavarz, A., Kadry, H., Lahooti, B., Al-Obaida, A., Ding, Z., ... Ahsan, F. (2020). Pulmonary-arterialhypertension (PAH)-on-a-chip: fabrication, validation and application. Lab on a Chip, 20(18), 3334-3345. doi:10.1039/d01c00605j. 